\title{
First direct evidence of meso-scale variability on ion-neutral dynamics using co-located tristatic FPIs and EISCAT radar in Northern Scandinavia
}

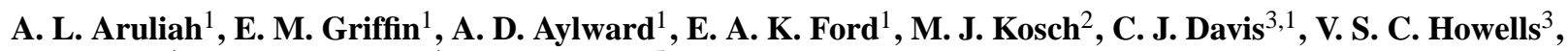 \\ S. E. Pryse ${ }^{4}$, H. R. Middleton ${ }^{4}$, and J. Jussila ${ }^{5}$ \\ ${ }^{1}$ University College London, 67-73, Riding House Street, London W1W 7EJ, UK \\ ${ }^{2}$ Department of Communications Systems, Lancaster University, Lancaster, LA1 4YR, UK \\ ${ }^{3}$ Space Science and Technology Department, CCLRC Rutherford Appleton Laboratory, Chilton, Didcot, Oxfordshire, OX11 \\ 0QX, UK \\ ${ }^{4}$ Institute of Mathematical and Physical Sciences, University of Wales Aberystwyth, Ceredigion SY23 3BZ, Wales, UK \\ ${ }^{5}$ Department of Physical Sciences, P.O. Box 3000, FIN-90014, University of Oulu, Finland
}

Received: 1 March 2004 - Revised: 8 November 2004 - Accepted: 9 November 2004 - Published: 31 January 2005

Part of Special Issue "Eleventh International EISCAT Workshop"

\begin{abstract}
This paper presents the first direct empirical evidence that mesoscale variations in ion velocities must be taken into consideration when calculating Joule heating and relating it to changes in ion temperatures and momentum transfer to the neutral gas. The data come from the first tristatic Fabry-Perot Interferometer (FPI) measurements of the neutral atmosphere co-located with tristatic measurements of the ionosphere made by the European Incoherent Scatter (EISCAT) radar which were carried out during the nights of 27-28 February 2003 and 28 February until 1 March 2003. Tristatic measurements mean that there are no assumptions of uniform wind fields and ion drifts, nor zero vertical winds. The independent, tristatic, thermospheric measurements presented here should provide unambiguous vector wind information, and hence reduce the need to supplement observations with information obtained from models of the neutral atmosphere, or with estimates of neutral parameters derived from ionospheric measurements. These new data can also test the assumptions used in models and in ion-neutral interactions. The FPIs are located close to the 3 radars of the EISCAT configuration in northern Scandinavia, which is a region well covered by a network of complementary instruments. These provide a larger scale context within which to interpret our observations of mesoscale variations on the scales of tens of kilometres spatially and minutes temporally. Initial studies indicate that the thermosphere is more dynamic and responsive to ionospheric forcing than expected. Calculations using the tristatic volume measurements show that the magnitude of the neutral wind dynamo
\end{abstract}

Correspondence to: A. L. Aruliah

(a.aruliah@ucl.ac.uk) contribution was on average $29 \%$ of Joule heating during the first night of observation. At times it either enhanced or reduced the effective electric field by up to several tens of percent. The tristatic experiment also presents the first validation of absolute temperature measurements from a common volume observed by independently calibrated FPIs. Comparison of EISCAT ion temperatures at an altitude of $240 \mathrm{~km}$ with FPI neutral temperatures show that $T_{i}$ was around $200 \mathrm{~K}$ below $T_{n}$ for nearly $3 \mathrm{~h}$ on the first night during a period of strong geomagnetic activity. This is inconsistent with energy transfer. Comparison with FPI temperatures from surrounding regions indicate that it could not be accounted for by height variations. Indeed, these first results seem to indicate that the $630-\mathrm{nm}$ emission did not stray too far from $240 \mathrm{~km}$. There were also apparent drops in $T_{e}$ at the same time as the anomalous $T_{i}$ values which are energetically implausible. Incorrect assumptions of composition or nonMaxwellian spectra are likely to be the problem.

Key words. Ionosphere (Auroral ionosphere; Electric fields and currents; Ionosphere-atmosphere interactions)

\section{Introduction}

This is a unique experiment where a common volume is observed by the EISCAT radar and 3 FPIs to permit independent and tristatic measurements of the ionosphere and thermosphere, respectively. The first true common volume observations were made by the Dynamics Explorer 2 spacecraft, which carried an FPI and spectrometer instrument to measure the neutral component, together with an ion drift 


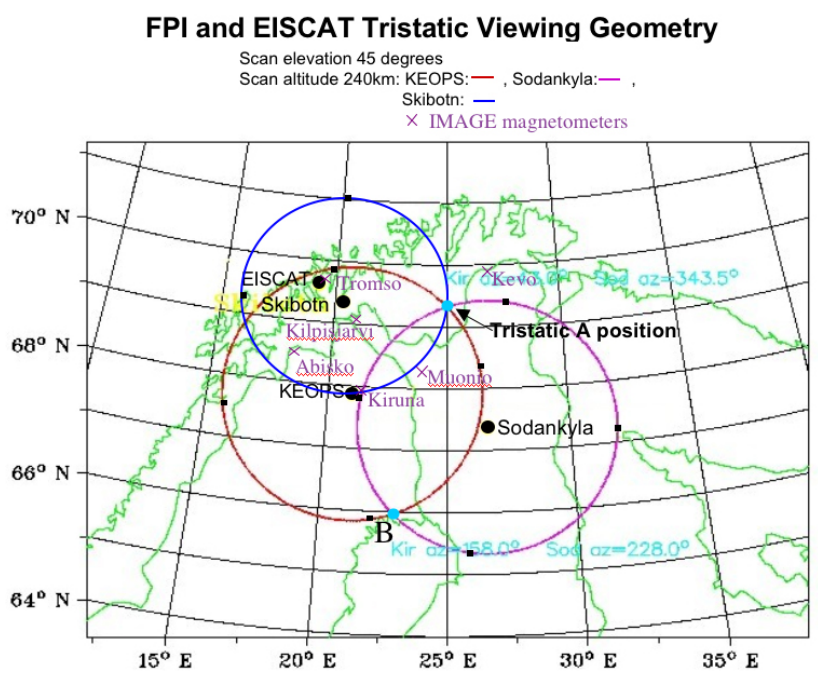

Fig. 1. Location of the 3 FPIs at Skibotn, KEOPS and Sodankylä and the EISCAT radar at Troms $\varnothing$. The circles show the field-ofview of the FPIs for elevation angles of $51.5^{\circ}$ for Skibotn and $45^{\circ}$ for KEOPS and Sodankylä. The dots indicate the positions of the volumes viewed by each FPI. Positions A and B are the tristatic and bistatic volumes, respectively. The locations of the IMAGE magnetometers are also given.

meter and retarding potential analyzer instrument for the ionospheric component (Killeen et al., 1984). The majority of previous ground-based experiments mainly investigated large-scale behaviour over a region of hundreds of kilometres using a single FPI with a radar (e.g. Cierpka et al., 2000; Aruliah and Griffin, 2001; Sakonoi et al., 2002). There are only a small number of published meso-scale investigations using two FPIs in close proximity (i.e. Greet et al., 1999; Ishii et al., 2001).

At present the mainland EISCAT radar is the only radar in the world that makes true tristatic observations of the ionosphere. This is achieved using a transmitter/receiver at Troms $\varnothing$ and receivers at Kiruna and Sodankylä. Other radars derive plasma velocities using a single transmitter/receiver and rely on beam-swinging techniques with the assumption that the plasma velocity field is unchanged between two directions of observation. The limitations of the beamswinging technique are presented by Etemadi et al. (1989) and are particularly pertinent since the small-scale variability of the ionosphere has now become a prime concern. Merging and reconnection of the solar wind with the geomagnetic field is no longer seen to be a steady-state phenomenon, but a series of irregular pulsed events resulting in highly variable plasma velocities (Lockwood et al., 1995). A major shortcoming of the models is that there are large disparities in the values of neutral winds and temperatures between model calculations and observations. The general circulation models (GCMs) use large-scale averaged electric fields and particle precipitation models which result in too much momentum transferred to the neutral gas, and too little Joule heating at high-latitudes. Put simply, the effect of applying a constant drag term (albeit a smaller force than the instantaneous force) compared with a semi-random force vector that swings rapidly about a near zero average value, results in a building up of velocities which are not observed in the real atmosphere. Similarly, the heating effect of a smoothly averaged plasma flow is significantly smaller than that of a randomly varying flow. The lack of consideration of small-scale variability is a serious limitation of the models and consequently an important new area of investigation.

Papers are beginning to appear that show that the highlatitude thermosphere also has small-scale variability (e.g. Conde et al., 2001; Aruliah and Griffin, 2001; Aruliah et al., 2004) and in particular with connection to gravity waves (Innis and Conde, 2002). This is important since the neutral winds and temperatures appear in several fundamental equations for ion-neutral dynamics and energetics. Unfortunately, the main sources of observation of the neutral component of the upper atmosphere are passive, such as optical emissions which are all spatially and temporarily localised, and satellite drag, which has its own spatial and temporal sacrifices in order to obtain global coverage. Consequently, the lack of available thermospheric data has meant that assumptions are frequently used instead of observations. As a result the assumptions of a slowly varying inertial medium are ingrained and the need for contemporaneous data collection is often overlooked. However, the substitution of model data brings problems, since models are an excellent tool for understanding general mechanisms, but are inadequate as a replacement since they will propagate the limitations of their assumptions. Even empirical models can only substitute for generic climatology studies.

\section{The tristatic experiment}

The first tristatic campaign was held during the period 16:30 04:30 UT on the nights of 27-28 February 2003 and 28 February until 1 March 2003. Figure 1 shows the location of the instruments in the auroral zone in Northern Scandinavia. The FPIs observe the red line emission at $630 \mathrm{~nm}$ of atomic oxygen which is the second most dominant nighttime auroral and airglow emission after the green line emission at $557.7 \mathrm{~nm}$, in the visible region. The height of the red line emission peak intensity is around $240 \mathrm{~km}$ (e.g. Solomon et al., 1988), thus the Doppler shifts and Doppler broadening of the emission allows for the calculation of the wind speeds and temperatures of the upper thermosphere.

The three FPIs are at the Sodankylä Geophysical Observatory in Finland $\left(67.4^{\circ} \mathrm{N}, 26.6^{\circ} \mathrm{E}\right)$, Skibotn in Norway $\left(69.3^{\circ} \mathrm{N}, 20.4^{\circ} \mathrm{E}\right)$ and the Kiruna Esrange Optical Site (KEOPS) in Sweden $\left(67.8^{\circ} \mathrm{N}, 20.4^{\circ} \mathrm{E}\right)$. Each FPI observes a $1^{\circ}$ field-of-view at an elevation angle of $45^{\circ}$ for the Sodankylä and KEOPS FPIs, and $51.5^{\circ}$ for the Skibotn FPI. A scanning mirror turns to allow for observation to the north, east, south, west and zenith, thus providing a large-scale context by creating a grid of FPI observations of winds, temperatures and intensities. The circles define the viewing area of 
each FPI, assuming an emission height of $240 \mathrm{~km}$. Two further positions are observed: position $\mathrm{A}$ is the tristatic common volume, where the fields-of-view of all three FPIs overlap, and position B is a bistatic common volume seen by the KEOPS and Sodankyla FPIs. As can be seen from Fig. 1, there are also other points where more than one FPI can view volumes that are in close proximity, such as KEOPS zenith with Sodankylä west and Skibotn south viewing volumes.

The EISCAT radar was in CP1-like mode. The CP1 mode is a fixed transmitter beam in the field-aligned direction, however, in this experiment the beam and the two receivers are not field-aligned, but are aimed at the common volume A $\left(69.4^{\circ} \mathrm{N}, 25.0^{\circ} \mathrm{E}\right)$, to make tristatic measurements. Further details of the operation of the FPIs may be found in Aruliah and Griffin (2001), and of the EISCAT radar in Rishbeth and Williams (1985).

The FPIs are not cross calibrated for intensity and so each has been scaled to match the KEOPS FPI intensity in the figures shown in this paper. Each FPI is of a different age and there are different detector sensitivities. Detector technology has progressed rapidly over the 10 years since the Skibotn FPI was built. The Skibotn FPI (intensified EEV detector) has an integration time of $60 \mathrm{~s}$, while the Sodankylä (EEV detector) and KEOPS (Andor detector) FPI have 40 and $20 \mathrm{~s}$, respectively. Consequently the time resolution to complete a cycle of observations is $3.5 \mathrm{~min}$ and $8.5 \mathrm{~min}$ for the KEOPS and Sodankylä FPIs, respectively. The Skibotn FPI has a cycle time of $13.9 \mathrm{~min}$, however, the tristatic A position is viewed twice in each cycle to improve the time resolution. The reason for the low time resolution is that the Skibotn FPI has a longer dead time owing to its more complex mechanical system which includes additional mirror elevation control. This accounts for why the Skibotn FPI misses the variability and dramatic peaks in intensity seen by the other 2 FPIs and also misses out on data when the signal-to-noise ratio is too poor. The intensities of the Sodankylä and Skibotn FPIs have been scaled to the KEOPS intensities by multiplying by factors of 11.4 and 1.49 , respectively. Having scaled the data, the difference in intensities can be attributed to several possible contributions:

1. Longer FPI integration times and lower time resolutions smooth out the sharp peaks and troughs seen by the highest resolution FPI at KEOPS.

2. If the emission peak height is greater or smaller than $240 \mathrm{~km}$, the line-of-sight observing volume of each FPI will over- or undershoot $\mathrm{A}$ and so there is no longer a common volume.

3. The height integrated intensities from the 3 FPI viewpoints are different,owing to the variations in the emission profiles over the fields-of-view.

\section{Cloud scatter.}

Comparison of the intensities and temperatures of all the look directions allow for an investigation of variability on scales of tens of kilometres to a few hundred kilometres.
The spatial scale size of the thermosphere will determine whether (b) and (c) make much difference to the heightintegrated intensity. Current models such as the GLOW model (Solomon et al., 1988) have too coarse a spatial resolution, owing to their dependence on parameters derived from global models, such as the International Reference Ionosphere (IRI) (Bilitza, 1997) and MSIS (Picone et al., 2002), to show any significant variation for less than $5^{\circ}$ latitude. This is a severe limitation of global models, since the upper atmosphere at high-latitudes is highly spatially variable, and the region covered by the 3 FPIs is around $6^{\circ}$ latitude by $18^{\circ}$ longitude. As an example, this region would be represented by only 3 points in the CTIP model, which currently has a spatial resolution of $2^{\circ}$ latitude by $18^{\circ}$ longitude (e.g. Millward et al., 1996). However, the model's spatial limitation can be helped by using a 1-min time step and equating Local Time variations with longitude variations.

The geometry of the location of the FPIs is not ideal. The best configuration would be for the 3 FPIs to be at the corners of an equilateral pyramid with the common volume at the apex. The FPI geometry is determined by the location of the facilities of the three geophysical institutes housing the EISCAT radars. The Skibotn FPI points almost to the east to view the tristatic A position. As a result, it measures an extremely small meridional component. Thus, the tristatic zonal component is reliable, while the meridional component is dominated by the KEOPS and Sodankylä line-of-sight measurements and shows a poor match with the bistatic calculation and therefore is not shown. The inversion of the tristatic matrix produces a poor determination of the vertical component since it is much smaller than the other two components, and this also is not shown. The equations used to determine the tristatic vector are given in the Appendix.

For each FPI the winds are calculated by observing the shift of the 630-nm peaks from a zero Doppler shift peak position. Since there is no convenient laboratory source of $630 \mathrm{~nm}$, it is necessary to determine the zero Doppler shift position by using the vertical observation and a neon calibration lamp observation. The calibration lamp also provides a measure of the stability of the FPI to fluctuations in ambient conditions. The wavelength of the neon calibration lamp is $630.4 \mathrm{~nm}$ and so cannot be used as the zero Doppler shift position. Instead, the assumption is made that the average vertical wind over a complete night is zero, which roughly complies with the conservation of mass law, i.e. there is no net loss of mass at a given height over a $24-\mathrm{h}$ period. The longer the night, the more valid the assumption. Once the mean nighttime offset of the vertical emission peak from the calibration lamp peak is calculated, the offset is added to the calibration lamp peak to create a zero Doppler shift peak position throughout the night. Further discussion of the vertical wind is given in the following section.

This tristatic campaign is the first experiment that has allowed for cross-calibration for thermospheric neutral temperatures. Neutral temperatures are derived from the Doppler broadening of the $630-\mathrm{nm}$ emission line. The instrument function needs to be derived using a laser profile and 

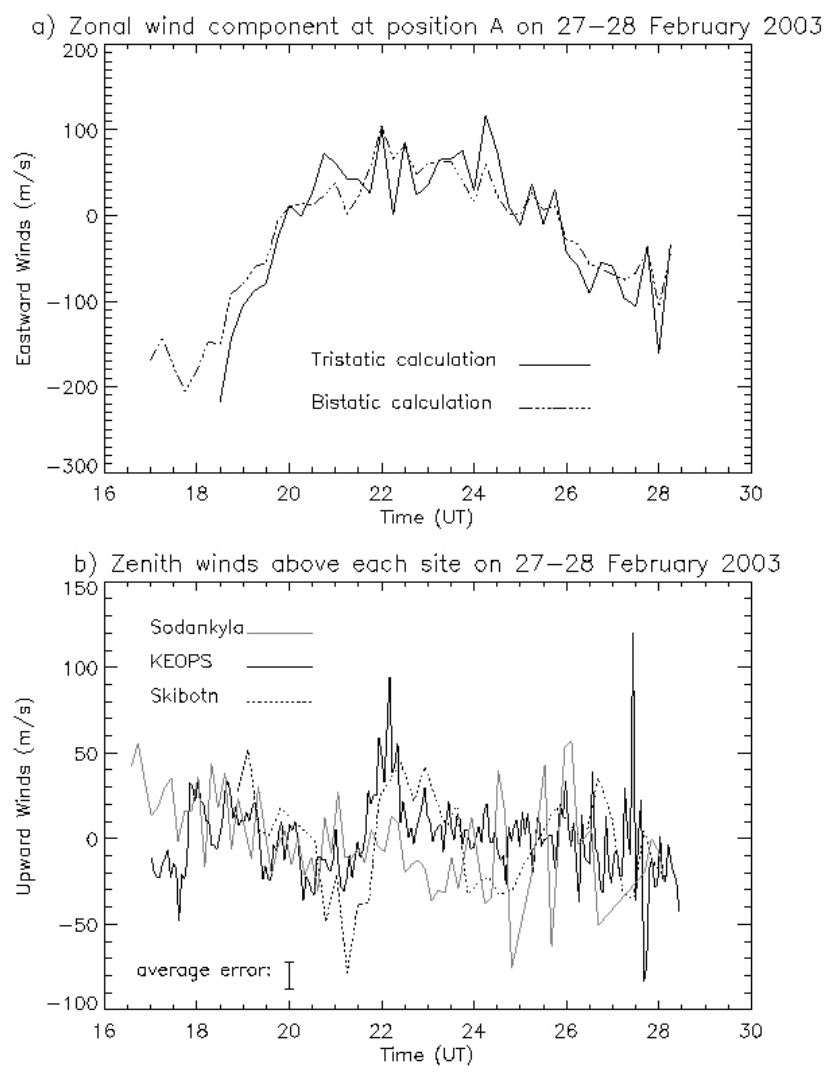

Fig. 2. (a) Comparison of zonal wind component calculated using tristatic (all 3 FPIs) and bistatic (only KEOPS + Sodankylä) lineof-sight measurements on the night of 27-28 February 2003. (b) Comparison of the vertical wind component observed by each of the 3 FPIs on the night of 27-28 February 2003.

deconvolved from the fringe profile in order to calibrate the FPI and determine an absolute temperature. Two of the FPIs, Skibotn and Sodankylä, were absolutely calibrated using HeNe laser profiles. As the KEOPS FPI was not absolutely calibrated the measurements must be offset to produce agreement.

Neutral temperatures determined in this way may differ from the ambient thermospheric temperature if there is a significant contribution to the overall intensity from nonthermalised atomic oxygen. This would artificially increase the observed temperature, as demonstrated by Shematovich et al. (1999). Sipler and Biondi (2003), however, have shown that in their FPI Doppler temperature analysis, the contribution of the non-thermalised component of the total emission was always less than $20 \mathrm{~K}$, i.e. much less than their error estimates, for a range of solar activity conditions. Further, the main contribution to the temperature increase was from higher altitudes, above the peak emission height.

We have used the combination of instruments available for the current tristatic arrangement to demonstrate that for the majority of the time our peak altitude appeared to be close to our nominal $240-\mathrm{km}$ peak height. This should ensure that we did not suffer from a significant contribution to the Doppler temperature from non-thermalised emission. However, we are aware that the Sipler and Biondi (2003) conclusions were for mid-latitudes and that while the analysis techniques are essentially similar, the details may alter the impact of the non-thermal emission, so we are working to simulate these effects for our specific technique.

\section{Meso-scale variability of the high-latitude thermo- sphere}

\subsection{Variability of thermospheric winds}

Figure 2a shows the calculated zonal wind component for position A on the night of 27-28 February 2003. A comparison is made between the true tristatic calculation that uses the line-of-sight winds from all 3 FPIs and the bistatic calculation that uses the 2 FPIs with the highest time resolution (KEOPS and Sodankylä). The bistatic calculation requires the assumption that the vertical wind component is zero to solve the equations. This is a commonly used assumption based on the observation that the vertical wind component is on average an order of magnitude smaller than the horizontal component. The discrepancy of up to $50 \mathrm{~m} / \mathrm{s}$ between the tristatic and bistatic wind values is more due to the failure of this assumption rather than because the three FPIs are not observing a common volume. Figure $2 b$ shows the individual vertical components measured above each of the FPI sites. The location of the FPIs are such that Skibotn and KEOPS are at the same geographic longitude, separated by about $250 \mathrm{~km}$, while KEOPS and Sodankylä are at the same geographic latitude, also separated by about $250 \mathrm{~km}$. As noted earlier, the sensitivities of the FPIs were different, hence the various time resolutions. Inspection of the vertical wind plot shows that the winds were individually highly variable over this small area. The vertical winds ranged between $\pm 50 \mathrm{~m} / \mathrm{s}$, with a few excursions to a maximum of $120 \mathrm{~m} / \mathrm{s}$ upwards at 03:26 UT. The wind error is dependent on the signal-to-noise ratio, thus the vertical wind error bars were $\pm 10 \mathrm{~m} / \mathrm{s}$ up to midnight when the intensities were high. After midnight they rose to around $\pm 20 \mathrm{~m} / \mathrm{s}$ on average as the intensities became low.

The error due to a change in the peak emission height may be estimated by using the line-of-sight winds from the cardinal point observations, to determine the gradient of the wind field. Taking a possible extreme value, if the emission height was $50 \mathrm{~km}$ higher than $240 \mathrm{~km}$ and the line-of sight volumes over-reached position A, then the average change in the magnitude of the wind for this night would have been only around $10 \mathrm{~m} / \mathrm{s}$. Thus, the difference between the tristatic and bistatic calculations was mainly due to the vertical wind assumption.

Similar trends in the nighttime variation of the vertical winds were seen independently in each of the data sets, especially the large upwelling at 22:00 UT which was occurred when an auroral arc passed through this region. The vertical wind seen by both the KEOPS and Skibotn FPIs around this time rose sharply to around $100 \mathrm{~m} / \mathrm{s}$. Prior to the 
upwelling, Skibotn showed strong downwelling to a maximum of $-78 \mathrm{~m} / \mathrm{s}$ at 21:16 UT while KEOPS and Sodankylä showed smaller downwelling during all or part of the period between 21:00-22:00 UT.

These are very large vertical winds but similar sized vertical winds at high latitudes have been reported by other workers (e.g. Price et al., 1995). Earlier observations were treated with scepticism, owing to the consideration of the large energies required to move the atmosphere vertically. Shinagawa et al. (2003) carried out a modelling study of vertical winds generated by a moving auroral arc based on an EISCAT experiment. The study produced maximum vertical winds of $20 \mathrm{~m} / \mathrm{s}$ which were less than the observed winds. This will be discussed in the section on ion-neutral coupling below.

The large upwelling resulted in a single data point indicating a sharp drop of nearly $100 \pm 32 \mathrm{~m} / \mathrm{s}$ in the tristatic zonal wind component at 22:00 UT. The tristatic winds were calculated with a resolution of $15 \mathrm{~min}$, which is around the time taken for this rapid velocity spike to occur. However, the time resolution of the KEOPS line-of-sight measurements was far higher, as shown in Fig. 3. There were 6 data points between 21:54-22:12 UT from the KEOPS tristatic A measurements, with an error of $\pm 16 \mathrm{~m} / \mathrm{s}$, which clearly show that this was a real geophysical observation rather than due to instrumental or observational error.

Conde and Smith (1998) show a similar drop in the horizontal wind field accompanying an upwelling which they have called the "doldrums". They suggest that this is the result of the advection of low velocity gas from the E-region up to the F-region. If this is the case, it might be expected that the upwelling gas package would carry E-region temperatures, but cooler due to adiabatic expansion. The radar measurements of $T_{i}$ in the E-region were $\sim 500 \mathrm{~K}$ which would be indicative of $T_{n}$ at this altitude. The Sodankylä FPI tristatic A measurements showed no particular trends in $T_{n}$ around this time that might indicate the intrusion of an E-region gas parcel. The FPI measurements of neutral temperature are described in more detail in the temperatures section below. Furthermore, the main Joule heating at 22:00 UT was in the F-region where $N_{e}$ and hence the conductivity was highest. Thus, there would have been little reason for a gas parcel to rise to the hotter F-region altitudes from the E-region through buoyancy alone.

However, both the Sodankylä tristatic A and North measurements of $T_{n}$ showed a larger average $T_{n}$ in the period of the upwelling, i.e. $\left\langle T_{n}>=1152 \mathrm{~K}\right.$ (tristatic A) and $1132 \mathrm{~K}$ (North) for the period 22:00-22:30 UT. This was followed by a drop in the average temperature to $<T_{n}>=1062 \mathrm{~K}$ (tristatic A) and $1045 \mathrm{~K}$ (North) for the period 22:30-23:00 UT followed by a rise back up to $1102 \mathrm{~K}$ (tri A) and $1078 \mathrm{~K}$ (North) for the period 23:00-23:30 UT. This temperature trend was also seen in the KEOPS tristatic A $T_{n}$ measurements, although the magnitudes involved are unresolved as the temperatures have not been calibrated. So it may be possible that the drop in temperature can be interpreted as evidence of cooler E-region gas which took half an hour to cool the F-region by nearly $100 \mathrm{~K}$. These temperature data are

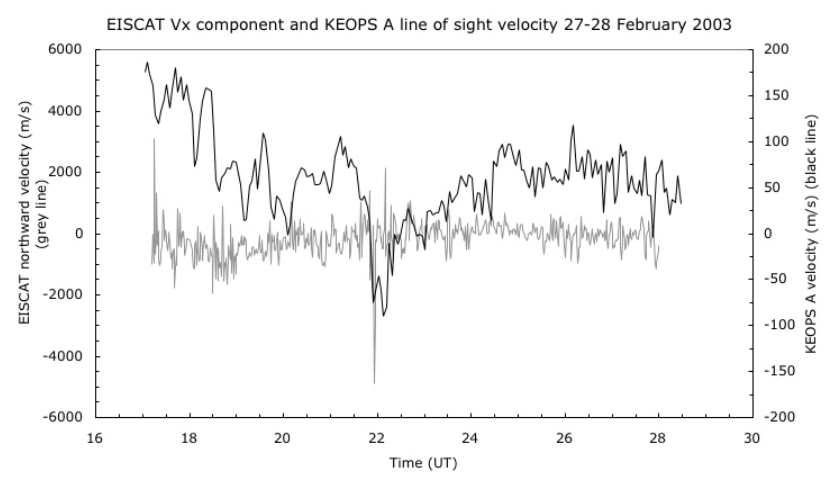

Fig. 3. Comparison of the EISCAT northward component of the field-perpendicular ion velocity (left-hand scale) with the KEOPS FPI line-of-sight thermospheric wind (right-hand scale). The rapid thermospheric response to the ion velocity spike was largely due to a large upwelling caused by Joule heating as shown in Fig. 2 b.

presented later in this paper under the section for ion-neutral coupling.

Alternately, instead of considering a dip in temperature around 23:30 UT, the temperatures around 22:00 UT and 23:00 UT could probably represent temperature rises due to heating and they do indeed match with peaks in the 630-nm intensities when there was particle precipitation.

The last evidence against the doldrums theory for explaining this behaviour comes from taking all the KEOPS azimuthal line-of-sight winds and calculating the horizontal wind field using the KEOPS zenith observation to give allowance for the vertical wind component. There does not appear to have been any distinct drop-off in speed that might indicate an upwelling from the E-region. Instead, this seems to have been a typical diverging wind field.

Figure $2 \mathrm{~b}$ illustrates that the assumption of a zero vertical wind at any one time is not correct, however, over a whole night the assumption is adequate for determining a zero Doppler position. The reliability of this procedure depends on the geomagnetic activity during the night. As shown by Aruliah and Rees (1995), the average nighttime vertical wind is zero for geomagnetically quiet conditions, but tends to have a small upward value during active conditions when the auroral region suffers from sustained periods of upwelling due to Joule heating. This is likely to introduce a systematic offset of $\sim 5 \mathrm{~m} / \mathrm{s}$. So it is gratifying to see that the 3 independently calibrated FPIs showed similar trends and variations in the vertical winds throughout the night despite sampling different regions of the upper atmosphere above each site. This indicates that the procedure used to determine the zero Doppler baseline is adequate.

Figure 3 shows that the large upwelling in the vertical wind around 22:00 UT corresponded to an extremely large and sudden increase in the ion velocity to around $5000 \mathrm{~m} / \mathrm{s}$ for the northward component in the plane perpendicular to the magnetic field. The grey line shows the ion velocity $\boldsymbol{V}$ and the black line shows the neutral wind $\boldsymbol{U}$. Note that the neutral 


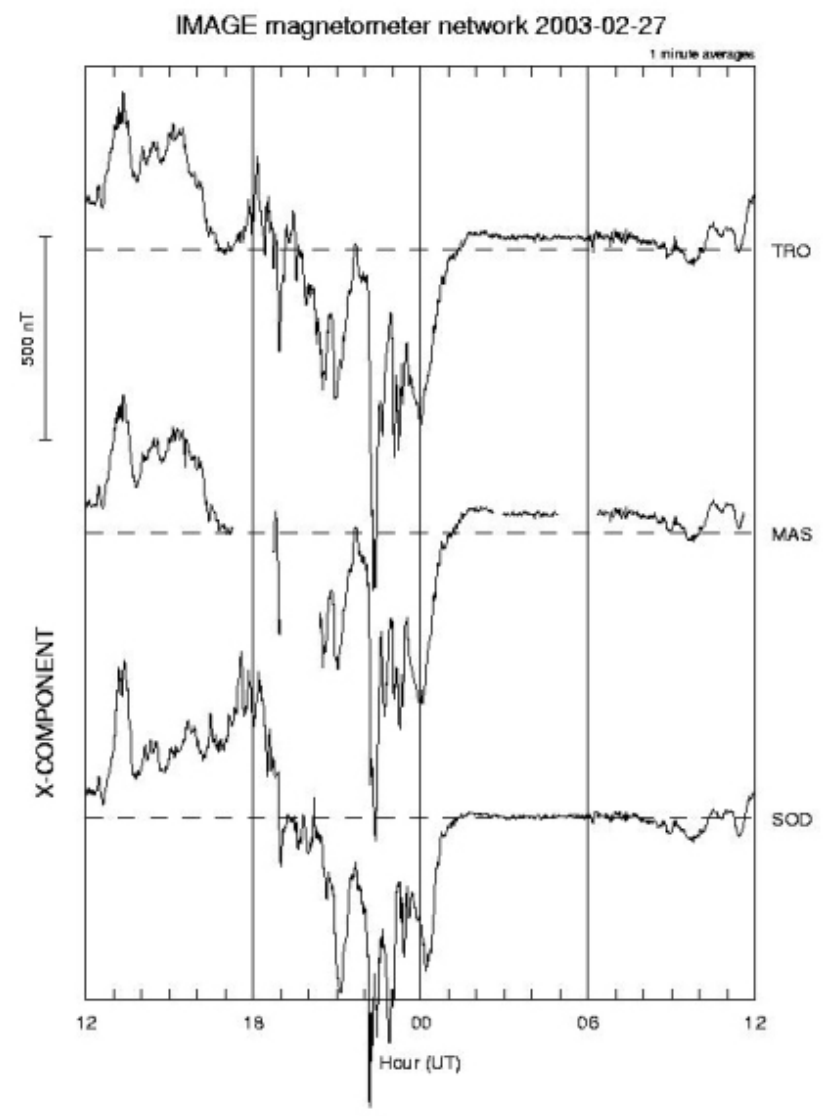

Fig. 4. IMAGE magnetometer traces from Troms $\varnothing$, Masi and Sodankylä showing the $B_{x}$ component on the night of 27-28 February 2003 for a latitude range of $67^{\circ}-70^{\circ} \mathrm{N}$.

winds were an order of magnitude smaller than the ion velocities. The ion velocity scale is to the left and the neutral wind scale to the right of the graph.

The neutral wind response to the sudden momentary ion velocity increase was more rapid than expected, although it was mainly in the vertical component rather than horizontal, as shown by Fig. 2 b. It is interesting that the effect of this sudden increase lingered in the neutral winds for a few ten's of minutes, as can be seen by the slow decline in the wind magnitude.

Price et al. (1995) have suggested that the sudden appearance of vertical winds may be caused by the advection of regions of upwelling into the field-of-view of their FPI rather than a sudden upward acceleration. It is possible that the simultaneous surge in ion velocity and neutral wind upwelling observed in Fig. 3 may be a coincidence rather than a cause and effect. In order to test this it would be necessary to determine the vertical wind field over the region covered by the FPIs. However, our own observations and previous studies (Crickmore, 1993) have already indicated that the scale size for the upper thermospheric vertical winds appears to be only a few $100 \mathrm{~km}$ in the auroral region. This makes us wary of extrapolating the zenith winds observed over the FPI sites out to the edges of the viewing circles which have a presumed radius of $240 \mathrm{~km}$. However, the sudden increase and lingering decrease in the neutral wind seem more likely to be a response to a surge of ion drag forcing than a passing of region of upwelling, which might be expected to have a more smoothly varying effect. Another point is that the upwelling is seen simultaneously at both KEOPS and Skibotn, which lie along the same meridian. There is no indication of the possibility of a zonally travelling front of upwelling appearing at Sodankylä, which is west of KEOPS, before (for a westward travelling front) or after (eastward) 22:00 UT. Further work arising from this experiment will combine modelling studies with these data to help resolve the issues uncovered.

The sudden increase in ion velocities was due to the presence of high electric fields within auroral arcs during a substorm expansion. Figure 4 gives an indication of the geomagnetic activity conditions on the night of 27-28 February 2003 by showing the perturbation of the $B_{x}$ component of the geomagnetic field observed by the IMAGE magnetometer chain. The response of the general ionospheric electron density distribution to the increased geomagnetic activity is shown in the sequence of three tomographic images in Fig. 5. The first image at 19:57 UT (Fig. 5a), before the time of increased activity, shows the increased electron densities of the auroral region in the northern field-of-view, with evidence of a boundary blob at the equatorward edge around $77-78^{\circ} \mathrm{N}$. By the next tomographic image at 21:45 UT (Fig. 5b) the auroral structure was essentially south of $77^{\circ} \mathrm{N}$ and extended to the low-latitude extreme of the field-of-view. A slight poleward retreat of the increased densities had occured by the tomographic image at 23:32 UT (Fig. 5c).

3.2 Ion-neutral coupling: first empirical confirmation of the importance of variability to Joule heating

It should be noted that average electric field models such as the Millstone Hill model (e.g. Foster, 1983) use average plasma velocities from the Millstone Hill radar smoothed over $2.5 \mathrm{~h}$ to calculate $\boldsymbol{V} \times \boldsymbol{B}$. A more recent electric field model by Weimer (1995) fits a spherical harmonic function to binned satellite measurements. The consequence of such smoothed electric fields when used in GCMs is that too much momentum is transferred to the neutral gas at high latitudes, resulting in winds that are up to two times larger than measured by FPIs (Aruliah and Griffin, 2001; Griffin et al., 2004), and too little heat is generated, resulting in temperatures that are hundreds of Kelvin smaller than measured by FPIs (Killeen et al., 1995). This has already been recognised as a problem and Codrescu et al. (2000) have addressed the temperature discrepancy by calculating the variability of the Millstone Hill plasma velocities and adding this as a parameter to the Foster average electric field model. However, it is proposed that Codrescu's analysis of the standard deviation may be a major underestimate of Joule heating since:

1. The original radar velocities in the database are already averaged over $2.5 \mathrm{~h}$, as mentioned above, while 
a) Tomographic Image: $27 \mathrm{Feb} 2003$ 19:57 UT Electron Density x $10^{11} \mathrm{~m}^{-3}$

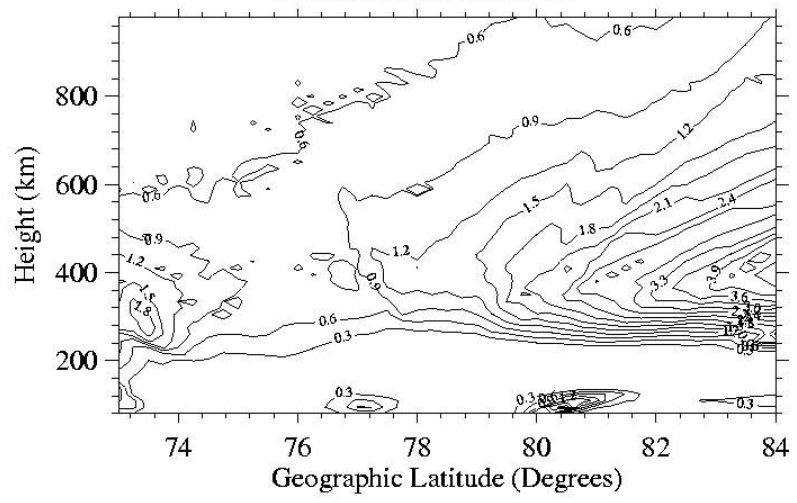

b) Tomographic Image: 27 Feb 2003 21:45 UT Electron Density x $10^{11} \mathrm{~m}^{-3}$

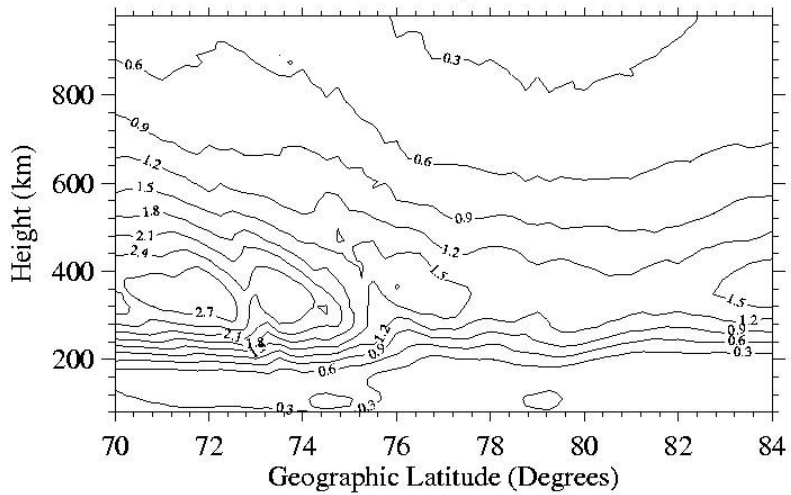

c) Tomographic Image: 27 Feb $2003 \quad 23: 32$ UT Electron Density x $10^{11} \mathrm{~m}^{-3}$

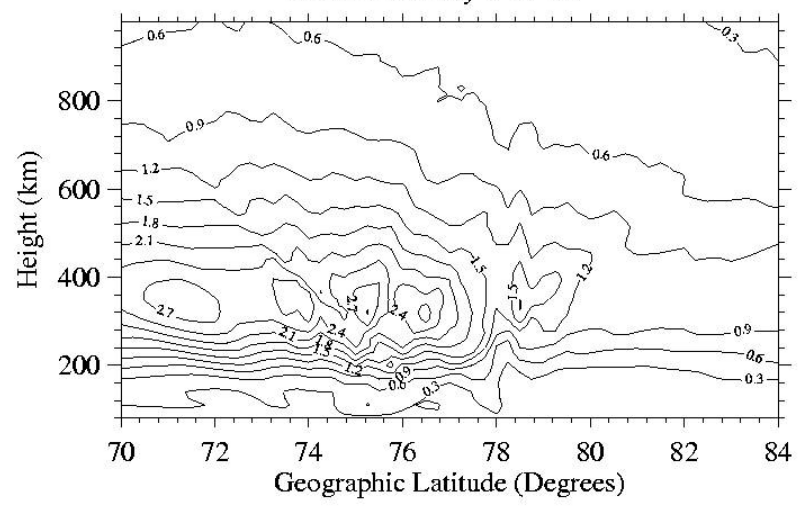

Fig. 5. Electron density tomographic images showing how the auroral oval expanded from (a) north of the FPIs' field-of-view at 19:57 UT to (b) to south of $77^{\circ} \mathrm{N}$ at $23: 45 \mathrm{UT}$ and then by (c) 23:32 UT retreating slightly poleward.

Lanchester et al. (1996) have shown variability down to resolutions of less than a second.

2. There is a spatial averaging over volumes that span a range of altitude and large horizontal range since the radar scan is a low-elevation, long range scan over hundreds of kilometres.

3. The binning of data according to geomagnetic and solar indices with coarse time resolution, such as $K_{p}$, which

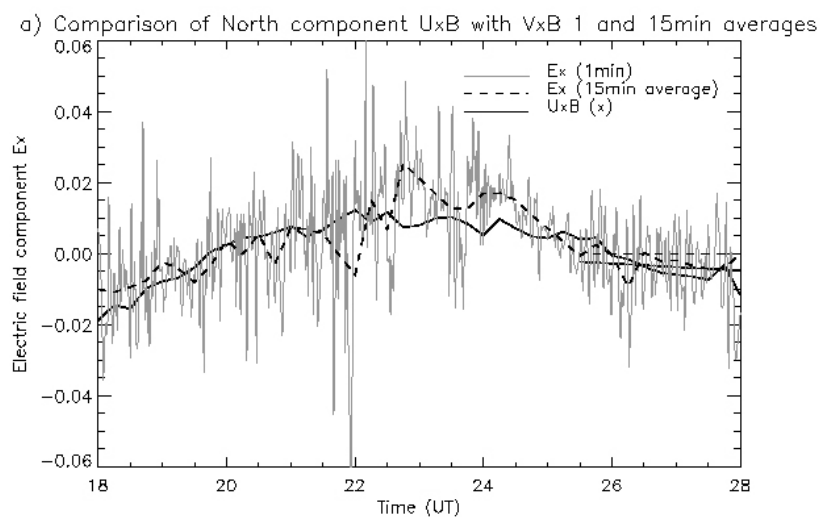

b) Comparison of East component $U \times B$ with $V \times B \quad 1$ and $15 m i n$ averages

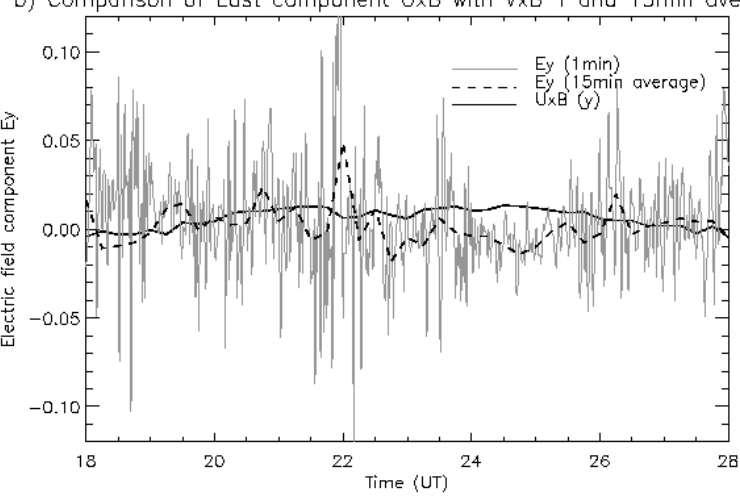

Fig. 6. Comparison of the north and east components of the magnetospheric electric field $(\boldsymbol{V} \times \boldsymbol{B})$ using 1-min and 15-min averages with the neutral wind dynamo $(\boldsymbol{U} \times \boldsymbol{B})$ on the night of 27-28 February 2003.

is a 3 -h index, results in considerable smoothing.

4. The heating effect of particle precipitation should also be considered. Satellite particle sensors with a finite time resolution, limited spectral energy resolution and range sample a complex 3-D pattern of precipitation via a 1-D cut over a limited geographic trajectory. These measurements are then converted into global particle precipitation models used in the GCMs. Although extremely useful for climatology studies, they suffer from the limitation of being a low resolution spatial average of what are highly localised heating phenomena. Thus, small-scale heating effects are likely to be severely underestimated.

All the high-latitude electric field models ignore the neutral wind dynamo because at high latitudes the neutral wind dynamo, is assumed to be an order of magnitude smaller than the magnetospheric dynamo (e.g. Mozer, 1973). However, the neutral wind speeds in the upper atmosphere are an order of magnitude larger than in the E-region, owing to the reduced densities and consequently fewer collisions in the upper atmosphere, and can reach a few hundreds of $\mathrm{m} / \mathrm{s}$ in magnitude (Killeen et al., 1995; Aruliah et al., 1996). 
The plots in Fig. 6 show a comparison of the F-region neutral wind dynamo $(\boldsymbol{U} \times \boldsymbol{B})$ with the magnetospheric dynamo $(\boldsymbol{V} \times \boldsymbol{B})$. The magnetospheric dynamo field was calculated using both the 1-min average $\boldsymbol{V}$ and the 15-min average. The 1-min average $\boldsymbol{V}$ was large and highly variable while, obviously, the 15-min average was fairly smoothly varying. The F-region neutral wind dynamo was also smoothly varying and had a magnitude that was significant in size compared with the 15-min average $\boldsymbol{V} \times \boldsymbol{B}$. The average magnitude of $\boldsymbol{U} \times \boldsymbol{B}$ was $50 \%$ of $\boldsymbol{V} \times \boldsymbol{B}$ during 27-28 February 2003, which is consistent with Killeen et al. (1984).

The important point of Fig. 6 is that the neutral wind had a steadily varying value through the night while the 1-min average values of the ion velocities had large erratic variations. This is implied by the dynamo electric fields. The consequence is that the random nature of the ion velocities and therefore ion drag will produce a smaller acceleration of the neutral gas than predicted by model simulations that use steady-state electric fields.

Figure 7a shows the Skibotn and KEOPS FPI neutral temperatures at the tristatic A position which is presumed to be at an altitude of $240 \mathrm{~km}$. These temperatures are compared with EISCAT ion temperatures at two altitudes $245 \mathrm{~km}$ and $294 \mathrm{~km}$, for 27-28 February 2003. Figure 7b shows the corresponding Joule heating calculations. In particular, Fig. $7 \mathrm{~b}$ shows the large difference introduced by including ionospheric variability into the calculation of Joule heating in the F-region. Thus, two sets of values representing Joule heating are plotted for the period 18:00-24:00 UT for the night of 27-28 February 2003. Joule heating is assumed to be proportional to $N_{e} * E_{\text {perp }}^{2}$, where $N_{e}$ is the electron density, which represents the conductivity, and $E_{\text {perp }}$ is the magnitude of the electric field perpendicular to the magnetic field direction. The black and grey lines show the Joule heating term calculated using 15-min and 1-min averaged values, respectively, of $\boldsymbol{V}$, to determine $\boldsymbol{E}=\boldsymbol{V} \times \boldsymbol{B}$.

There was a dramatic difference between the Joule heating calculated using the 1-min and 15-min averages. There were six peaks (at 18:30 UT, 19:45 UT, 20:15 UT, 20:45 UT 22:00 UT and 23:30 UT) in Joule heating using the 1-min averages and only 3 peaks (at 20:45 UT, 22:00 UT and 22:45 UT) using the 15-min averages. The size of the 1-min average Joule heating term indicates that Joule heating can be grossly underestimated by ignoring the variability of the ion velocities. The median of the ratios of the 1-min to 15 -min Joule heating measurements over the whole night is around $320 \%$. Figure 7 a shows that during the period 18:0019:00 UT the ion temperature rose sharply from $1200 \mathrm{~K}$ to over $1600 \mathrm{~K}$ before dropping quickly down. This seems to show a clear correspondence with a peak in the 1-min Joule heating term (Fig. 7b), while there was no corresponding increase in the 15-min Joule heating term.

What is interesting is that there does not appear to be such a clear correspondence between Joule heating and $T_{i}$ for the subsequent peaks. However, we would suggest that this is due to the breakdown of the assumptions used to calculate $T_{i}$ for the period 20:00-24:00 UT, resulting in anomalous
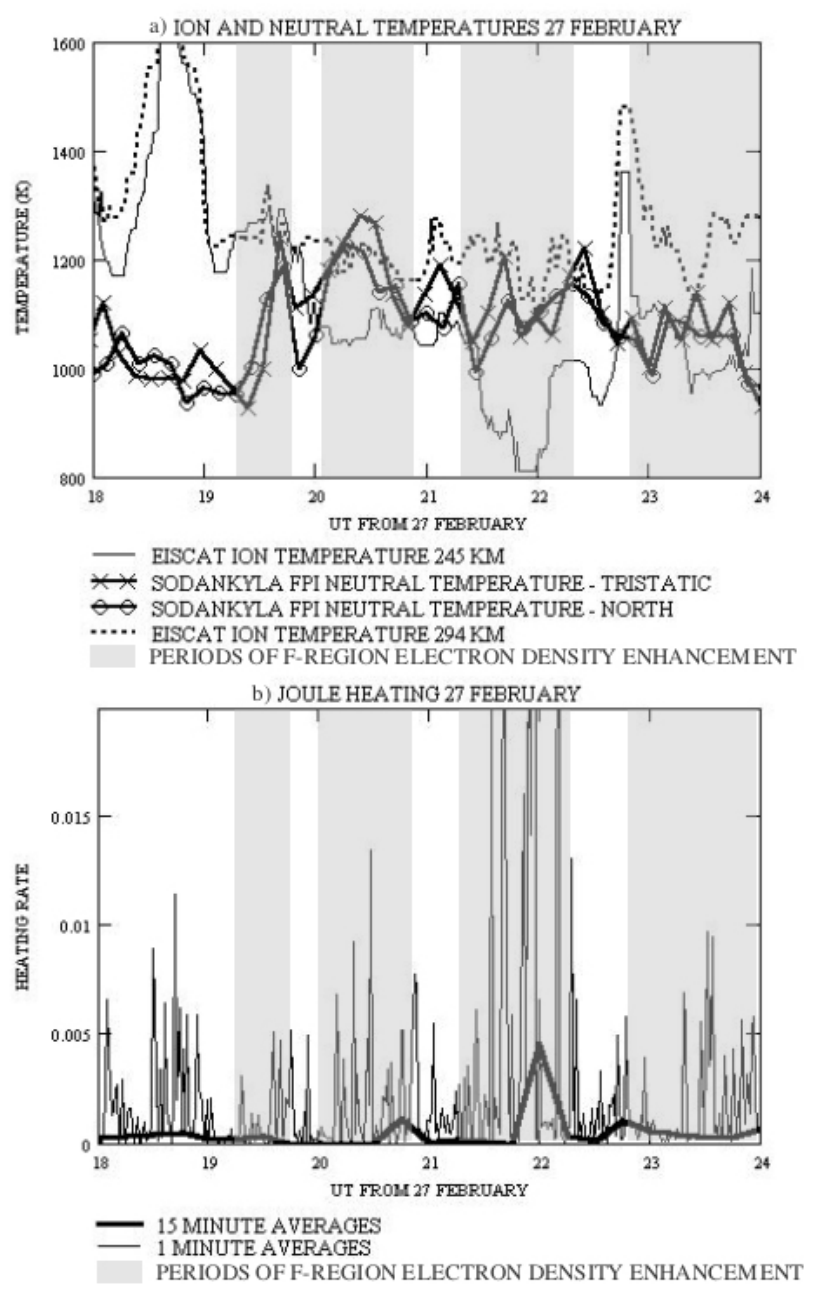

Fig. 7. (a) Comparison of Sodankylä FPI measurements of $T_{n}$ at tristatic A and North look directions with EISCAT $T_{i}$ at altitudes of $245 \mathrm{~km}$ and $294 \mathrm{~km}$ for the period 18:00-24:00 UT on the night of 27-28 February 2003. (b) Illustrating the importance of meso-scale ion velocity variability for determining Joule heating by comparing 1-min and 15-min average values for the same period as Fig. 7a. The periods of F-region intensifications of electron density are indicated by grey panels on Figs. $7 a$ and $b$.

temperatures. This is discussed in the following section about temperatures.

Further support for the importance of mesoscale variability is that the period of large Joule heating values between 21:30-22:30 UT corresponded to high vertical winds of up to $100 \mathrm{~m} / \mathrm{s}$, seen independently by the KEOPS and Skibotn FPIs. As stated previously, Shinagawa et al. (2003) carried out a modelling study of vertical winds generated by a moving auroral arc based on an EISCAT experiment by Oyama et al. (2001). The study produced maximum vertical winds of $20 \mathrm{~m} / \mathrm{s}$, which were considerably less than the observations, and the authors acknowledge the need for a larger energy flux. The sample frequency for their electric fields appears from their figures to have been $2 \mathrm{~s}$. Yet the variability does not appear to be as large as for our 1-min 


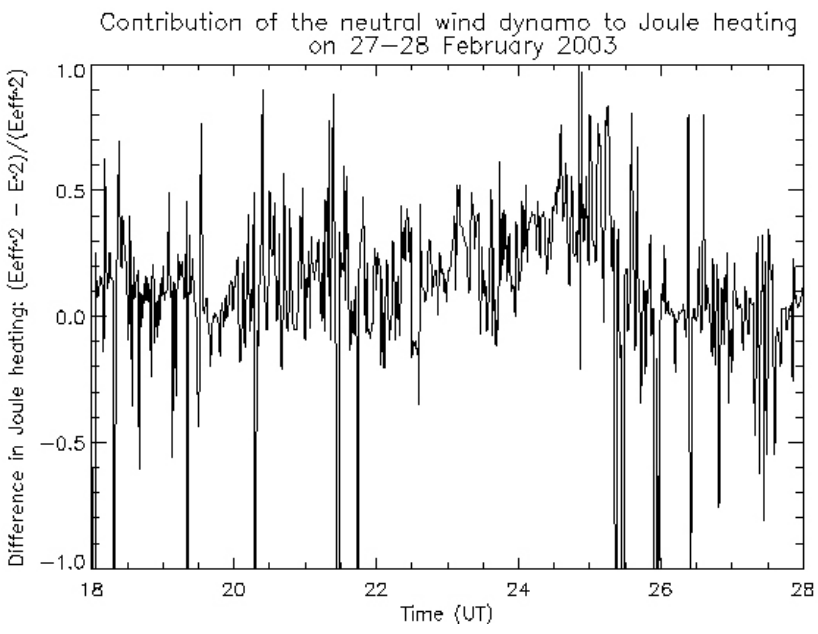

Fig. 7. (c) Percentage contribution of the neutral wind dynamo to Joule heating on the night of 27-28 February 2003.

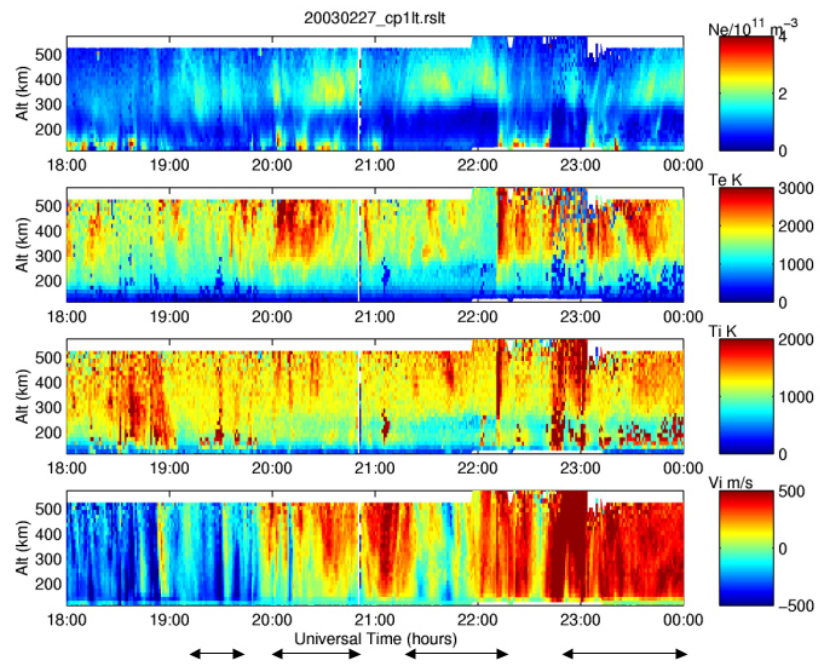

Fig. 7. (d) EISCAT $N_{e}, T_{i}, T_{e}$ and $\boldsymbol{V}$ data for the period 18:0024:00 UT on 27-28 February 2003. The periods of F-region intensifications of electron density are indicated by arrows.

radar measurements, which may imply that their data have been smoothed. Our observations suggest that large vertical winds may occur at intervals of high-temporal variation in Joule heating. This was not explored in the modelling study of Oyama et al. (2001). Our experiment appears to provide the first evidence that meso-scale variability must be taken into account when calculating Joule heating.

The Sodankylä thermospheric temperature response shown in figure 7 a differed from the ion temperatures. This is as expected since the neutral particle number density is 3 orders of magnitude larger, thus the thermosphere has a considerably larger heat capacity. There was no apparent response in $T_{n}$ to the first heating event between 18:00-19:00 UT. However, $T_{n}$ rose steeply by $200 \mathrm{~K}$ between 19:20 19:40 UT, fell sharply and rose again, reaching a maximum

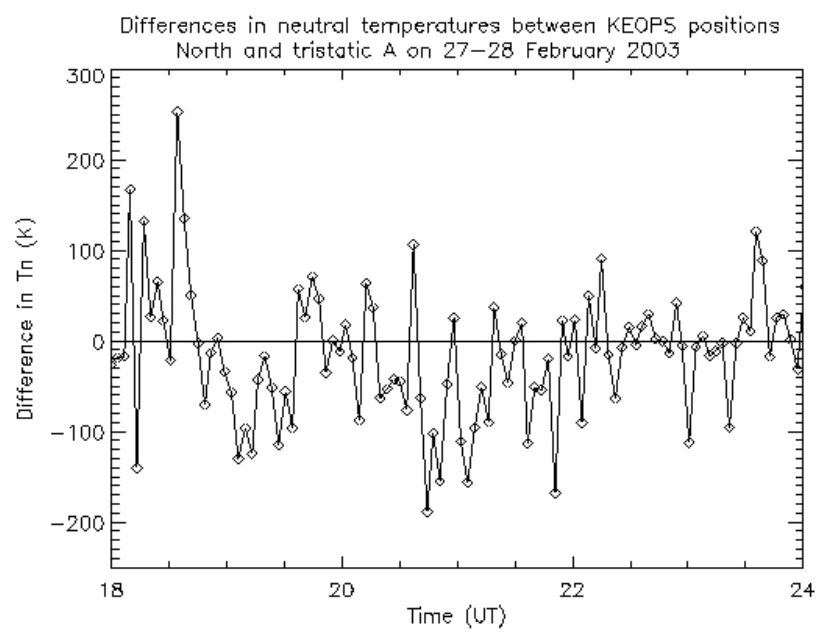

Fig. 7. (e) Deducing the thermospheric temperature difference along the radar beam from KEOPS FPI North and tristatic A measurements for the period 18:00-24:00 UT on 27-28 February 2003.

value of $1230 \mathrm{~K}$ around 20:30 UT. The neutral temperature then decreased, with several fluctuations, by around $250 \mathrm{~K}$ over $3.5 \mathrm{~h}$. In general, higher values of $T_{n}$ existed after 19:30 UT which seem consistent with the period of enhanced Joule heating calculated using the 1-min average Joule heating values shown in Fig. 7b.

A further comment is that Joule heating should be calculated in the frame of reference of the neutral wind, which means that the effective electric field is $\boldsymbol{E}^{\prime}=\boldsymbol{V} \times \boldsymbol{B}+\boldsymbol{U} \times \boldsymbol{B}$. Figure $7 \mathrm{c}$ shows the percentage difference made by the neutral wind dynamo in calculating the Joule heating term. This percentage difference is calculated using $\left(E_{\text {perp }}^{\prime 2}-E_{\text {perp }}^{2}\right) / E_{\text {perp }}^{\prime 2}$ and has both positive and negative values, i.e. the effect of the neutral wind dynamo was to both enhance and reduce magnetospheric Joule heating. The standard deviation of the percentage difference for the 1min averaged data ranges was $49 \%$ on this night (with several outliers that are extremely large). The net effect for the night of 27-28 February was an $8 \%$ increase in Joule heating. However, the size of the neutral wind dynamo contribution can be appreciated by calculating the average magnitude $\left.\mid E_{\text {perp }}^{\prime 2}-E_{\text {perp }}^{2}\right) / E_{\text {perp }}^{\prime 2} \mid$ of the neutral wind dynamo contribution to total Joule heating on this night, which was $29 \%$. This is consistent with a model study by Thayer et al. (1995) that has shown that ignoring the flywheel effect can introduce a $40 \%$ error in the calculation of height-integrated polar cap Joule heating during steady-state moderately active conditions. Thus, ignoring the neutral wind dynamo means that the redistribution of magnetospheric energy between Joule heating and acceleration of the thermosphere can be mistaken by several tens of percent. This is in addition to the effect of highly variable ion velocities compared with steady-state model conditions in increasing Joule heating and reducing the net momentum transfer to the neutral winds.

Figure $7 \mathrm{~d}$ shows panel plots of the electron densities, $N_{e}$, for all heights along the Troms $\emptyset$ beam, along with $T_{e}, T_{i}$ 

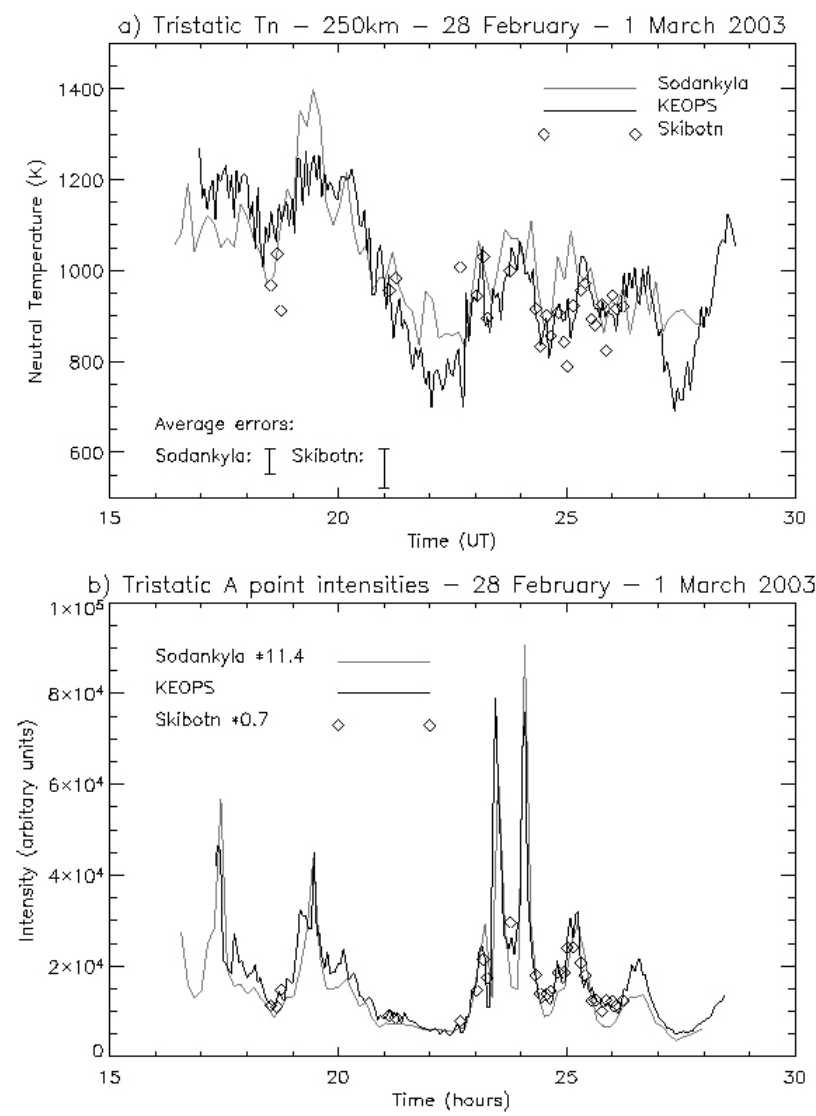

Fig. 8. (a) Comparison of thermospheric temperatures from independent measurements of a common volume by 3 FPIs on the night of 28 February-1 March 2003. (b) Comparison of the normalised intensities from the 3 FPIs for this night.

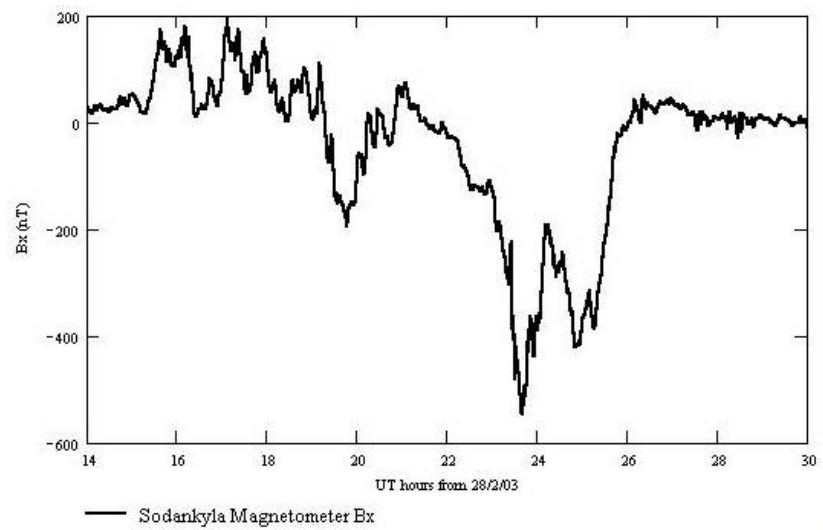

Fig. 9. IMAGE magnetometer traces showing the $B_{x}$ component on the night of 28 February-1 March 2003 at Sodankylä.

and $\boldsymbol{V}$. Between 22:00-23:00 UT it was necessary to move the Troms $\varnothing$ beam to a position $300 \mathrm{~km}$ above tristatic A, in order to improve the signal. This is shown in Fig. 7d as a shift in all the panel plots to a higher altitude range. There were 4 periods of E-region particle precipitation that can be observed in Fig. 7d from the enhancement of $N_{e}$ around $100-150 \mathrm{~km}$ altitude. The E-region particle precipitation was sporadic and occurred over periods between approximately 18:00-18:45 UT, 20:00-20:45 UT, 22:00-22:30 UT and 23:00-23:30 UT. The peaks in in-situ F-region Joule heating calculated using 1-min averages do not match the periods of E-region particle precipitation. In fact, the periods of particle precipitation generally encompassed the lowest values of Joule heating. However, the Joule heating peaks do match intensifications of the electron densities in the Fregion, i.e. in the periods 20:30-21:00 UT, 21:15-22:15 UT and 23:15-24:00 UT, as shown in Fig. 7d. These periods are indicated on Figs. $7 \mathrm{a}$ and $\mathrm{b}$ by grey panels, and on Fig. $7 \mathrm{~d}$ by arrows. These F-region intensifications may arise from lowenergy particle precipitation and also composition changes affecting production and loss of electrons, as well as equatorward transport of electrons from the polar cap.

\subsection{Tristatic neutral temperatures and anomalous ion tem- peratures}

Thermospheric neutral temperatures are an important measure of the energetics of the upper atmosphere. Given their importance, it is necessary first of all to establish the reliability of the temperature measurements from the FPIs. Figure 8a compares the derived neutral temperatures from the three FPIs at tristatic position A on the second night (28 February until 1 March 2003). The Skibotn and Sodankylä temperatures were absolutely calibrated using a He$N_{e}$ laser and ranged between 700-1400 K, with an average error of $\pm 50 \mathrm{~K}$. These represent the first reported comparisons of independently calibrated absolute temperature measurements from a common thermospheric volume. The grey lines represent the Sodankylä data and the open diamonds represent the Skibotn data. The black lines represent the uncalibrated KEOPS data, which have been offset by a constant value to match Sodankylä in order to compare trends.

The Skibotn temperatures have been filtered to exclude cloudy conditions identified from all-sky camera observations, and have also had profiles removed that were affected by CCD saturation. The remaining periods around 21:00-22:00 UT and during 02:00-03:00 UT on the night of 28 February-1 March 2003 demonstrate good agreement between the 3 sets of temperatures. The 630-nm intensities at the 3 sites showed a close match (Fig. 8b). This may be interpreted as all 3 FPIs observing the same volume. The comparison also revealed a large degree of temporal structure that appeared in all three sets of measurements. The time resolution at KEOPS was over two times better than that at Sodankylä and showed a great deal of small-scale temporal variation. When viewed in conjunction with the Sodankylä magnetometer data presented in Fig. 9 it is clear that the large increases in temperature after 18:00 UT and again after 22:00 UT coincided with large negative $B_{x}$ deflections and consequent electrojet activity. There was no evidence of a substantial time lag between the observation of the magnetometer deflections and the resultant increase in 

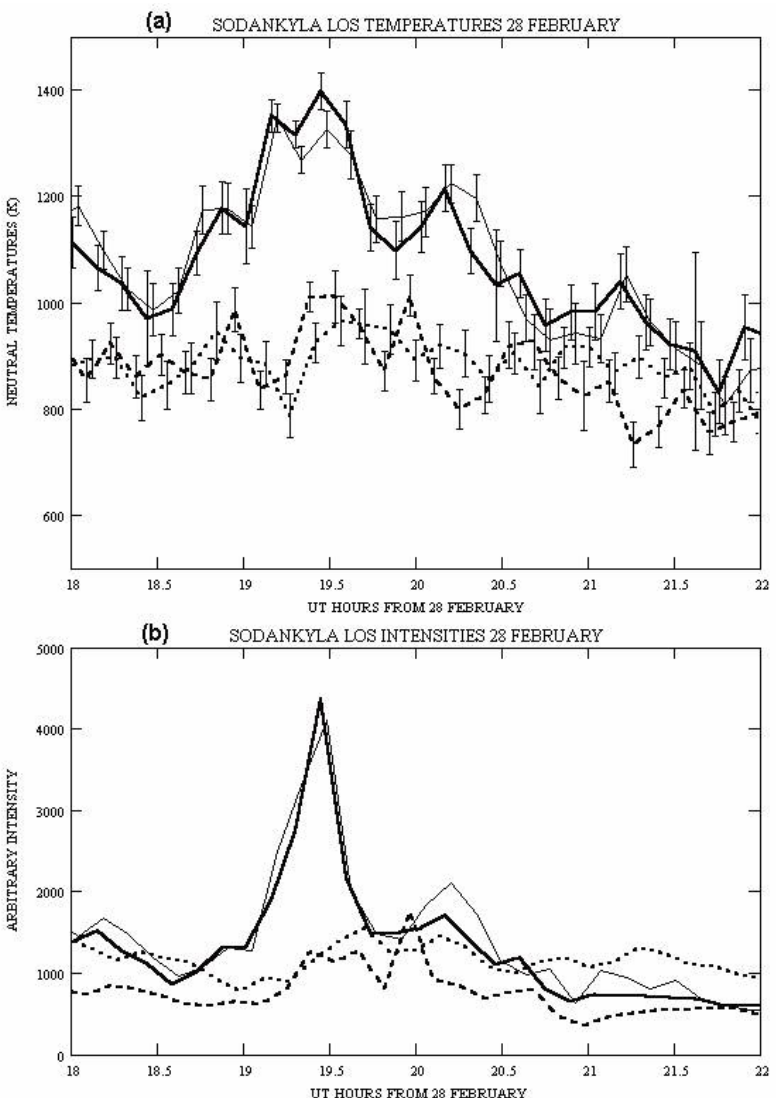

- TRISTATIC POSITION A

-... ZENITH

$\cdots$... BISTATIC POSITION B

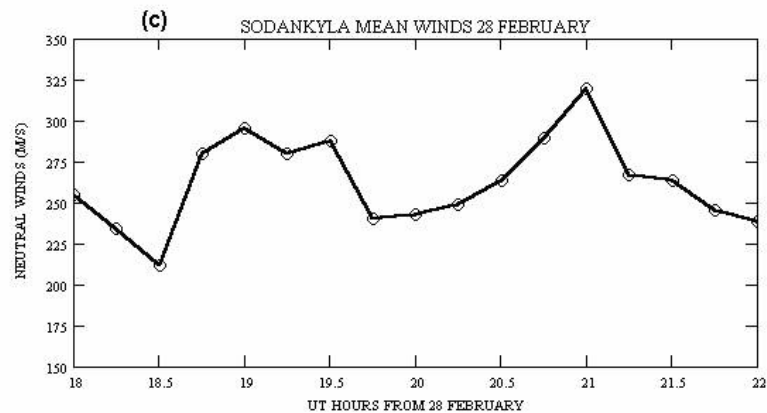

Fig. 10. (a) A close-up of the Sodankylä thermospheric temperature gradients from 18:00-22:00 UT on the night of 28 February01 March 2003. (b) The Sodankylä 630-nm intensities over the same period. (c) The average magnitude of the horizontal wind component calculated from the 4 cardinal directions from the Sodankylä FPI over the same period.

neutral temperature, thereby demonstrating a rapid thermospheric response.

The good agreement between the calibrated temperatures from Sodankylä and Skibotn in Fig. 8a would imply either that the two FPIs were measuring a common volume, or that the spatial variability of the neutral temperature was small. If the spatial variability of $T_{n}$ was small, then even if there had been a rise in the emission height (which would mean that the FPIs were overshooting the common volume) the 3 separate measured values would still agree.

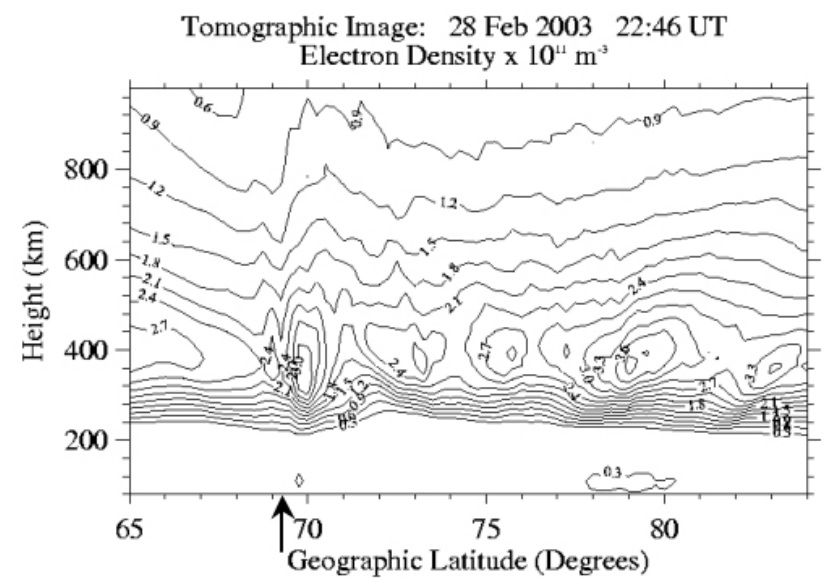

Fig. 11. Electron density tomographic images at $22: 46$ UT on 28 February 2003 showing that enhanced densities that were associated with the auroral activity extended to latitudes equatorward of Sodankylä. The arrow indicates the latitude of the tristatic A position.

However, in fact, there were sizeable meridional temperature differences over the field-of-view of $200-400 \mathrm{~K}$ between 16:00-21:00 UT on the night of 28 February-1 March 2003. Figure 10a focuses on showing the neutral temperatures for the period 18:00-22:00 UT from the Sodankylä North, Zenith, tristatic A and bistatic B observation points. The North and A values of $T_{n}$ were similar to each other, but significantly different from the Zenith and B values. The variation of the meridional temperature difference may be further investigated by comparing the temperatures observed to the north and south of Sodankylä for the period 18:50 20:10 UT. This gives an overall average meridional temperature difference of $270 \mathrm{~K}$, with a maximum difference of $466 \mathrm{~K}$ at 19:16 UT.

Figure 10b shows the corresponding intensities and Fig. 10c shows the average magnitude of the horizontal wind component calculated from the 4 cardinal directions from the Sodankylä FPI. It is clear that before 20:00 UT the auroral activity was to the north of Sodankylä, resulting in the larger intensities seen in the North and A positions. The large meridional gradient in temperature would appear to have been a consequence of auroral heating to the north. From 22:30 UT onwards, the auroral activity moved overhead, and the intensities and temperatures became more uniform. The tomography plot of electron density at 22:46 UT (Fig. 11) confirms this by showing that enhanced densities associated with the auroral activity extended to latitudes equatorward of Sodankylä.

It is also possible that the sharp increase and decrease in the temperature gradient may have been the consequence of a rise in the 630-nm emission height. If it is assumed that the temperature gradient remained constant but that the emission height had risen, then the emitting volumes seen by the FPI to the north and south of Sodankylä would have been further apart, which could account for the increase in tem- 
perature gradient. However, the emission height would need to rise by $70 \%$ to produce such a large increase in the temperature gradient. This is too large a rise to be plausible over a horizontal scale of several hundred kilometres, since the energy required to lift the atmosphere would be very great. Another argument against a rise in the emission altitude is that the North and tristatic A intensities and temperatures remained close in values throughout this period. A rise in altitude would have meant that their respective sampled volumes would have consequently spread apart and the values would have become different.

Figure 10c shows that before 22:00 UT the magnitudes of the horizontal wind were high and ranged between 200-300 m/s. In particular, between 18:45-1930 UT the magnitudes were nearly $300 \mathrm{~m} / \mathrm{s}$. The large size of these winds probably corroborates the existence of a large temperature gradient and consequently large pressure gradient driving these winds.

The absolute calibration of the Sodankylä temperatures allows a further important observation to be made. Going back to the first night of observations on the night of 27-28 February 2003, a comparison of $T_{n}$ from the Sodankylä FPI with $T_{i}$ calculated from the EISCAT data for a height of $245 \mathrm{~km}$ (Fig. 7a) showed an anomaly in $T_{i}$ - there was an extended period between 19:50-22:40 UT when $T_{i}<T_{n}$. The reliability of the measurement of $T_{n}$ comes from the comparison with the independent measurements of $T_{n}$ from the other two FPIs. Therefore, these values of $T_{i}$ are unlikely to be correct since the ionosphere is less than $0.1 \%$ of the composition of the upper atmosphere, and consequently, through ion-neutral collisions, the ion temperatures must be at least as high as the neutral temperature. One possible error in the computation of $T_{i}$ arises from the assumption of a composition that is totally atomic oxygen and the other is that the radar spectra are non-Maxwellian and consequently not fitted appropriately.

The evidence for changing the composition is ambiguous. The period between 21:20-22:20 UT corresponded to a large upwelling in the neutral winds, as shown in Fig. 2b, which may have increased the proportion of molecular species at this height. However, the period between 20:00-20:40 UT corresponded to downwelling in the neutral winds, which would be unlikely to change the mean molecular mass and therefore does not provide enough support for the composition theory.

The suggestion that $T_{i}$ is incorrectly calculated is supported by Fig. 7d. Whenever there was precipitation in the Fregion (around $400 \mathrm{~km}$ ) the electron temperature $T_{e}$ dropped by a few hundred Kelvin. This is clearly evident in the 2 periods centred on 19:16 UT and 19:37 UT and the periods: 20:27-20:48 UT, 21:35-21:53 UT, 22:00-22:19 UT and 23:50-24:00 UT. Despite the increased electron densities caused by precipitation, which would have increased the conductivity and hence Joule heating, $T_{e}$ should have remained fairly constant since electron heating is very small and is primarily due to plasma wave activity (e.g. Schlegel and St.-Maurice, 1981). The implication is that the standard procedure for determining $T_{e}$ is incorrect, and thus $T_{i}$ will
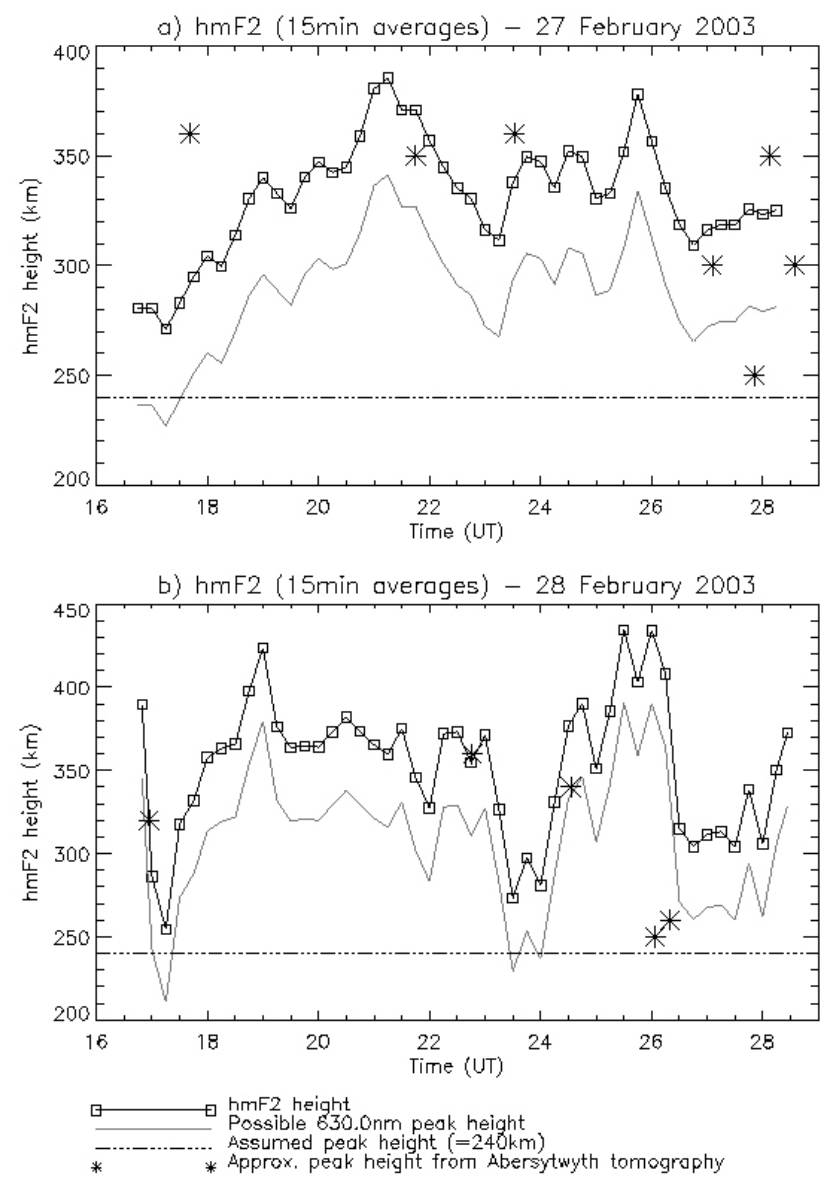

Fig. 12. Variation of $h m \mathrm{~F} 2$ on the nights of (a) 27-28 February 2003 and (b) 28 February-1 March 2003 from EISCAT and tomography data. It is assumed that the $630-\mathrm{nm}$ peak emission height is $240 \mathrm{~km}$ (dot-dashed line). This assumption is compared with an assumption that the peak height is about $50 \mathrm{~km}$ below $h m \mathrm{~F} 2$ (dotted line).

be wrongly calculated too since $T_{i} / T_{e}$ is the parameter determined from the radar spectra. Anomalous decreases in $T_{e}$ have been proposed as a flag indicating incorrect assumptions of composition or the presence of non-Maxwellian radar spectra by McCrea et al. (1995).

If the $T_{i}$ values were correctly calculated, then a possible cause for the anomalous $T_{i}-T_{n}$ comparison arises from the height variation of the red line peak emission altitude. Figure $7 \mathrm{a}$ also shows the EISCAT $T_{i}$ at $294 \mathrm{~km}$ altitude. Comparison of $T_{i}$ at $245 \mathrm{~km}$ and $294 \mathrm{~km}$ shows that before 20:00 UT there was only a small difference in $T_{i}(<100 \mathrm{~K})$ with respect to height, so determination of the altitude of the common volume is not critical. After 20:00 UT there was a large difference, up to a maximum of $400 \mathrm{~K}$, which means the altitude used for comparison of $T_{n}$ and $T_{i}$ becomes very sensitive. At $294 \mathrm{~km}$ there were no longer anomalous periods when $T_{i}<T_{n}$ which may imply that this altitude provides a more likely common volume. The tristatic experiment assumes a common volume at an altitude of $240 \mathrm{~km}$. However, Fig. 12a shows that between 20:00-20:40 UT $h m \mathrm{~F} 2$ rose to an altitude of around $350 \mathrm{~km}$, and between 21:20-22:00 UT 
the altitude was around $375 \mathrm{~km}$. Thus, an altitude of $300 \mathrm{~km}$ may be acceptable as the altitude of the 630-nm emission peak if it is assumed that the peak is one scale height below the $h m \mathrm{~F} 2$ peak, although this is considerably higher than expected.

If the $T_{i}$ values are correct, then an explanation is required for the large difference in $T_{i}$ measured at altitudes $245 \mathrm{~km}$ and $294 \mathrm{~km}$ that appeared after 20:00 UT. This time corresponded to a switch in the line-of-sight ion velocities from blue shifted (NWW direction) to red shifted (SEE direction), as shown in Fig. 7d. This may indicate that the heat energy was being transported up the field lines so that the F-region remained hot while the lower altitudes cooled. However, this explanation does not address the extremely low temperatures at $245 \mathrm{~km}$ after 20:00 UT, which reached as low as $800 \mathrm{~K}$.

The radar data from $245 \mathrm{~km}$ and $294 \mathrm{~km}$ represents a horizontal as well as vertical spatial difference since the elevation angle of the Troms $\emptyset$ beam is $45^{\circ}$. This means that comparison may be made with FPI measurements from other viewing directions, in particular a comparison of the KEOPS FPI $T_{n}$ to the north of KEOPS with the KEOPS $T_{n}$ at position A. The difference between the two temperatures is an indication of the thermospheric temperature gradient along the Troms $\varnothing$ beam (see Fig. 1) and will define the minimum possible value of $T_{i}$ along the beam. Figure $7 \mathrm{e}$ shows that the temperature difference was rarely more than $\pm 200 \mathrm{~K}$. During the period 20:00-24:00 UT, not only was the $T_{n}$ difference much smaller than the $T_{i}$ difference, but it was in the wrong direction, since $T_{n}$ to the north of KEOPS was on average hotter. This casts further doubt on the reliability of the values of $T_{i}$ at $245 \mathrm{~km}$.

Resolving the cause of these anomalies is our next venture; it is either the influence of increased molecular ion composition or non-Maxwellian spectra in the EISCAT data; determining or what altitude should be used for the comparison of $T_{i}$ and $T_{n}$ is also increasing. Furthermore, tristatic common volume experiments are the most likely way to achieve this.

\subsection{Variation of the 630-nm peak emission altitude}

The EISCAT volume of observation is known since it is an active radar, but passive airglow observation depends on the 630-nm peak emission height, which is assumed to be $240 \mathrm{~km}$ (e.g. Solomon et al., 1988). However, if the 630-nm emission height is different, then the FPIs over/undershoot the tristatic volume. It should be possible to estimate the height of the $630 \mathrm{~nm}$ emission from the EISCAT measurement of $h m \mathrm{~F} 2$, since it is assumed to be approximately 1 scale height $(40-50 \mathrm{~km})$ below $h m \mathrm{~F} 2$ (e.g. Makela et al., 2001). Figure 12 shows that there was considerable deviation from this assumption by plotting $h m \mathrm{~F} 2$ for the two campaign nights, 27-28 February 2003 and 28 February-1 March 2003. The values of $h m F 2$ are greater than $300 \mathrm{~km}$ for most of both nights, which implies that the FPIs were overshooting the common volume for significant periods.

The height of the $\mathrm{F} 2$ peak obtained by radio tomography at a latitude of $70^{\circ} \mathrm{N}$ is shown by the asterisks in Fig. 12. The tomography heights are in broad agreement with the trend seen in the $h m \mathrm{~F} 2$ measured by the EISCAT radar, though with a lower peak height occurring between about 02:00 and 04:00 UT. Whilst there is clear agreement in the trend, the absolute values of the peak altitudes inferred from the tomographic images should be treated with some caution due to the incomplete observing ray-path geometry for the experimental technique. The lack of quasi-horizontal ray-paths results in limited information of the vertical ionospheric distribution being available for the reconstruction process (Pryse, 2003).

Despite the likely variation in the $630-\mathrm{nm}$ peak height throughout the night, the independently measured intensities from the 3 FPIs matched very well on the 2 campaign nights of 27-28 February and 28 February-1 March 2003 (Figs. 13b and c). In contrast, the night of 26-27 February (Fig. 13a) showed the effect of light scatter by clouds over Sodankylä and Skibotn through the night. Cloud scatter raises the whole background level, thus reducing the signal-to-noise ratio and also the directional information is lost, resulting in a poor match in intensities. However, by 03:00 UT the cloud had cleared and so the Sodankylä intensities rose to match the KEOPS intensities. The Skibotn intensities matched KEOPS well from the beginning of the night through to about 21:45 UT, after which the sky became overcast and the intensities dropped.

The assumption of a peak 630-nm emission altitude of $240 \mathrm{~km}$ can be further tested by taking advantage of the tristatic geometry and complementary instrumentation in the region. In Fig. 14 we present a comparison of the 630$\mathrm{nm}$ intensity for a 2-h period from 21:30 UT to 23:30 UT on 27-28 February 2003 as measured by the Sodankylä and KEOPS FPIs, together with a Meridian Scanning Photometer (MSP) co-located with the Sodankylä FPI. The intensities have been arbitrarily scaled to allow for a comparison of the major features. The MSP was oriented azimuthally towards the tristatic volume for the duration of the tristatic experiment and scanned from elevations of $20^{\circ}-75^{\circ}$. The figure shows the MSP intensities at $45^{\circ}$ elevation, which was the same as the elevation angle of the Sodankylä FPI. These intensities are compared to both the KEOPS tristatic and the Sodankylä North intensities. The reason for the comparison with Sodankylä North intensities is that if the peak emission altitude had been $300 \mathrm{~km}$, rather than $240 \mathrm{~km}$, then the volume observed by KEOPS would have been much closer to Sodankylä North than to the Sodankylä tristatic position (see Fig. 1 for geometry). Figure 14 shows a close agreement between the KEOPS FPI tristatic A observation and the Sodankylä MSP measurements which consequently gives confidence that the peak emission altitude was closer to $240 \mathrm{~km}$ than $300 \mathrm{~km}$.

Unfortunately, this contradicts the suggestion that the problem of the anomalous ion temperatures period (when $T_{i}<T_{n}$ around $240 \mathrm{~km}$ altitude) may be solved by presuming that the FPI was sampling a volume around $300 \mathrm{~km}$ altitude. 

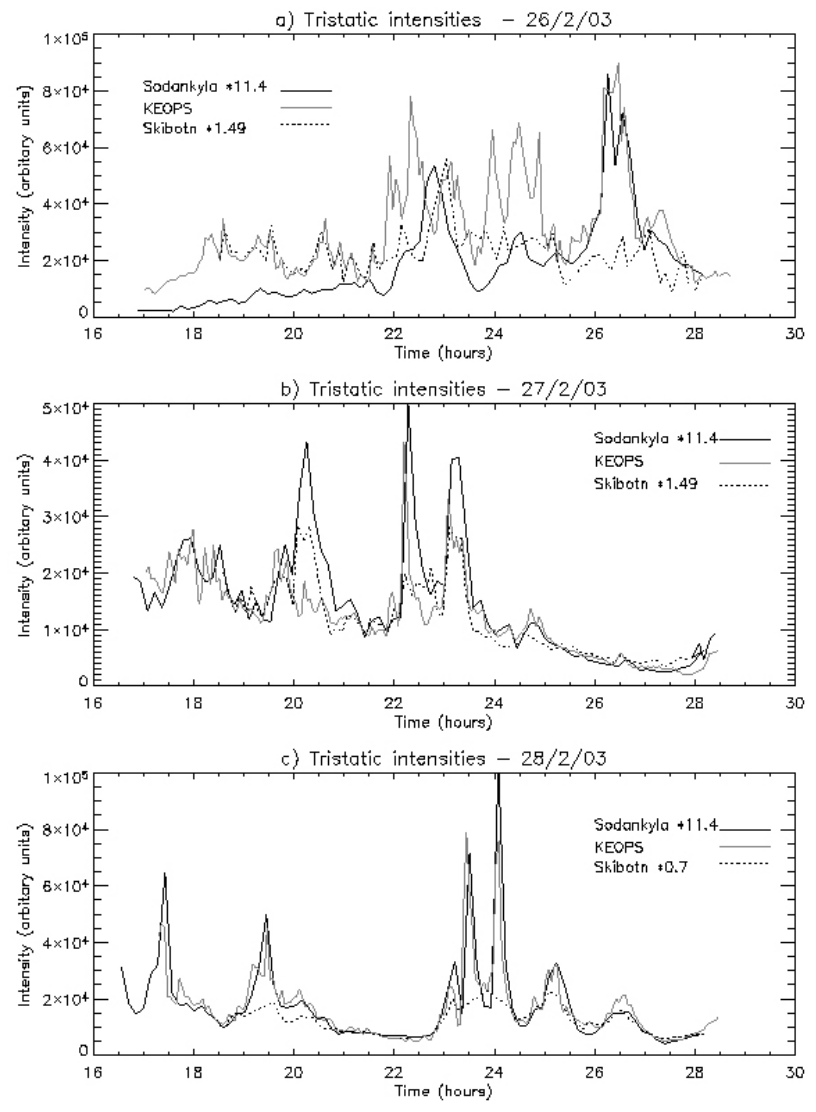

Fig. 13. Comparison of intensities from the 3 FPIs on 3 consecutive nights: (a) 26-27 February 2003, (b) 27-28 February 2003 and (c) 28 February-1 March 2003.

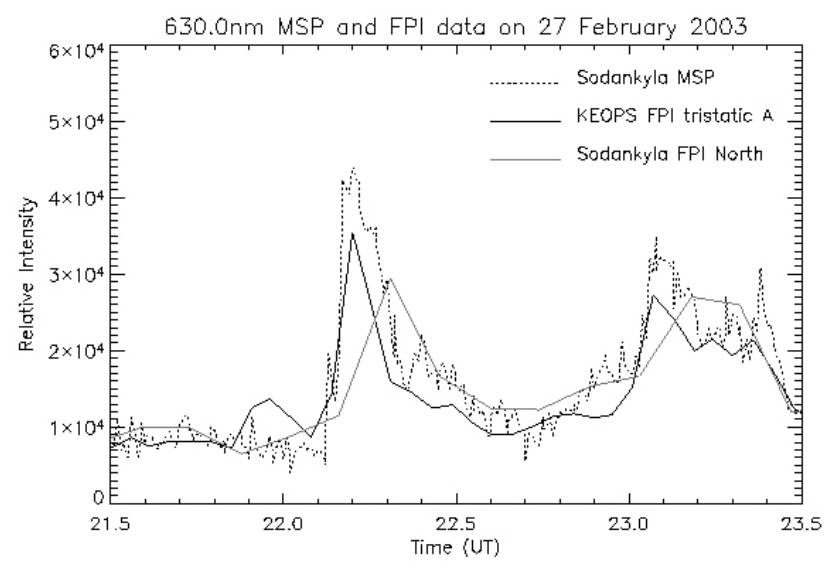

Fig. 14. Investigation of the 630-nm emission height by comparison of features seen by the Sodankylä MSP with the KEOPS and Sodankylä FPIs on the night of 27-28 February 2003.

\section{Preliminary conclusions}

This tristatic FPI-EISCAT radar experiment presents evidence of the rapid response of the thermosphere to ion drag on the meso-scale. High temporal variability in thermospheric temperatures and winds are demonstrated, which varied significantly over time scales of a few minutes and over distances of a few hundred kilometres. As a result, the prevailing view of the inertial thermosphere can no longer be justified on the meso-scale, except as the coarsest of assumptions, and certainly not in storm situations.

The tristatic FPI measurements present the first ever comparison of absolute temperatures from independently calibrated FPIs. True thermospheric temperatures are vitally important as a measure of the energetics of the upper atmosphere. The FPIs provided direct measurements of $T_{n}$ rather than derived values from radar measurements which rely on assumptions from models. The 3 different line-of-sight measurements showed a good agreement which confirms the reliability of the experimental method in determining absolute temperatures.

The most significant finding is that the neutral and ion temperature response appears to have a better match with Joule heating calculated from the highly variable 1-min plasma velocities rather than 15-min averages for the night of 27-28 February 2003. There was a $320 \%$ increase in the Joule heating when using the 1-min average ion velocities compared with the 15-min averages, owing to the stochastic motion of the ions which increases friction between the ions and neutrals. This is the first direct evidence of the effect of smallscale variability on Joule heating. It is important because the current GCMs ignore small-scale variability, and thus underestimate Joule heating, by using smoothed high-latitude average electric field models. This would account for the low model temperatures which can be hundreds of Kelvin lower than observed directly by FPIs and the low model vertical winds $(<20 \mathrm{~m} / \mathrm{s})$ which are several times smaller than observed. It has taken many years for the observations of large vertical winds $(>50 \mathrm{~m} / \mathrm{s})$ to be taken seriously.

The interpretation of the Joule heating-temperature relationship is complicated by an extended period of anomalous ion temperatures when $T_{i}<T_{n}$. However, we propose that the anomaly indicates flaws in the assumptions used in deriving $T_{i}$, possibly due to the existence of non-Maxwellian spectra, incorrect assumptions of the molecular ion composition or misidentification of the height of the common volume. The height is not thought to be the problem because comparison between auroral features observed in FPI intensities and meridian scanning photometers seem to indicate that the 630-nm emission height does not stray too far from $240 \mathrm{~km}$.

Further support for the inclusion of the variability of the plasma velocities in GCMs is that it should also reduce the net momentum transferred from the ions to the neutrals, resulting in smaller neutral winds. This would improve agreement with the wind speeds measured by FPIs. Model winds at high latitudes can be up to twice as large as observed winds. However, the discrepancy between observations and models in allocating magnetospheric energy between Joule heating and acceleration of the neutral gas is too complex to be resolved by a simple transfer of energy from one form to the other. For example, as a rough order of magnitude calculation, the difference in kinetic energy between a model 
wind of $300 \mathrm{~m} / \mathrm{s}$ and FPI wind of $200 \mathrm{~m} / \mathrm{s}$ corresponds to a temperature difference of only $30-40 \mathrm{~K}$, which is not enough to account for the model neutral temperatures being a few hundred Kelvin lower than the FPI temperatures. The reduction in the model winds needs to be brought about by allowing for a random stochastic acceleration of the neutrals rather than a steady acceleration. This can probably be achieved by parameterization in a similar manner to that used for Joule heating by Codrescu et al. (2000).

The F-region neutral wind dynamo has been shown to be around half the magnitude of the 15-min average magnetospheric dynamo. This also significantly modifies the redistribution of magnetospheric energy between Joule heating and acceleration of the thermospheric gas. The study of smallscale ion-neutral interactions is proving to be extremely complex.

\section{Appendix A}

Theoretically, the derivation of a tristatic wind vector may be achieved by setting up and solving the simultaneous equations for the 3 line-of-sight measurements in the following manner:

Let the neutral wind vector be $\boldsymbol{U}=U_{x} \mathbf{i}+U_{y} \mathbf{j}+U_{z} \mathbf{k}$.

And the direction vector for the line-of-sight observation be $\boldsymbol{r}=\sin \theta \cos \phi \mathbf{i}+\sin \theta \sin \phi \mathbf{j}+\cos \theta \mathbf{k}$, where $\mathbf{i}, \mathbf{j}$ and $\mathbf{k}$ are orthogonal axes with positive directions being geographic north, geographic east and vertically down, respectively. The angles $\theta$ and $\phi$ are the standard spherical coordinate system definitions, i.e. $\theta$ is measured from the $\mathbf{k}$ axis and $\phi$ lies in the $\mathbf{i}, \mathbf{j}$ plane and is measured from the $\mathbf{i}$ axis.

Thus the line-of-sight component winds $U_{l o s}$ from each site may be determined from the following equations:

$$
\begin{aligned}
& U_{\text {glos }}=\boldsymbol{U} \cdot \boldsymbol{r}_{\boldsymbol{g}} \quad \text { for KEOPS } \\
& U_{f l o s}=\boldsymbol{U} \cdot \boldsymbol{r}_{f} \quad \text { for Sodankylä } \\
& \mathrm{U}_{\text {mlos }}=\boldsymbol{U} \cdot \boldsymbol{r}_{\boldsymbol{m}} \quad \text { for Skibotn. }
\end{aligned}
$$

These 3 equations may be given in matrix form as $\mathbf{U}_{\text {los }}=\mathbf{R}$.U. Thus, $\mathbf{U}=\mathbf{R}^{-1} \mathbf{U}_{\text {los }}$.

The success of this calculation requires good geometry and the assumption that all three line-of-sight wind measurements come from the same volume. The optimal geometry is that the 3 sites and the observed volume form an equilateral pyramid. The observation of a common volume depends on the actual height of the 630-nm emission peak, which for this experiment was expected to be $240 \mathrm{~km}$.

Acknowledgements. The APL team would like to acknowledge funding from the Lapbiat grant, administered by the Sodankylä Geophysical Observatory, together with their generous help in logistics. Also acknowledging PPARC grant PPA/G/O/2001/00484. EISCAT is an International Association supported by Finland (SA), France (CNRS), the Federal Republic of Germany (MPG), Japan (NIPR), Norway (NFR), Sweden (NFR) and the United Kingdom (PPARC). We also thank the institutes who maintain the IMAGE magnetometer array and ESRANGE KEOPS facility.

Topical Editor M. Lester thanks M. Conde and another referee for their help in evaluating this paper.

\section{References}

Aruliah, A. L. and Rees, D.: The trouble with vertical winds: Geomagnetic, seasonal and solar cycle variations in high latitude thermospheric winds, J. Atmos. Terr. Phys., 57, 597-609, 1995.

Aruliah, A. L., Farmer, A. D., Rees, D., and Brandstrøm, U.: The seasonal behaviour of high latitude thermospheric winds and plasma velocities observed over one solar cycle, J. Geophys. Res., 101, 15 701-15 711, 1996.

Aruliah, A. L., and Griffin, E. M.: Meso-scale structure in the highlatitude thermosphere, Ann. Geophys., 19, 37-46, 2001.

Aruliah, A. L., MüllerWodarg, I. C. F., and Schoendorf, J.: The consequences of geomagnetic history on the high-latitude thermosphere and ionosphere: Averages, J. Geophys. Res., 104, 28073 $28088,1999$.

Aruliah, A. L., Griffin, E. M., McWhirter, I., Aylward, A. D., Ford, E. A. K., Charalambous, A., Kosch, M. J., Davis, C. J., and Howells, V. S. C.: First tristatic studies of meso-scale ion- neutral dynamics and energetics in the high-latitude upper atmosphere using co-located FPIs and EISCAT radar, Geophys. Res. Lett., 31, L03802, doi:10.1029/2003GL018469, 2004.

Bilitza, D.: International Reference Ionosphere-Status 1995-1996, Adv.Space Sci., 20, 1751-1754, 1997.

Cierpka, K., Kosch, M. J., Rietveld, M., Schlegel, K., Hagfors, T.: Ion-neutral coupling in the high-latitude F-layer from incoherent scatter and Fabry-Perot interferometer measurements, Ann. Geophys., 18, 1145-1153, 2000,

SRef-ID: 1432-0576/ag/2000-18-1145.

Conde, M. and Smith, R. W.: Spatial structure in the thermospheric horizontal wind above Poker Flat, Alaska, during solar minimum, J. Geophys. Res., 103, 9449-9471, 1998.

Conde, M., Craven, J. D., Immel, T., Hoch, E., Stenbaek-Nielson, H., Hallinan, T., Smith, R. W., Olson, J., Sun, Wei, Frank, L. A., and Sigwarth, J.: Assimilated observations of thermospheric winds, the aurora, and ionospheric currents over Alaska, J. Geophys. Res., 106, 10 493-10 508, 2001.

Codrescu, M. V., Fuller-Rowell, T. J., Foster, J. C., Holt, J. M., and Cariglia, S. J.: Electric field variability associated with the Millstone Hill electric field model, J. Geophys. Res., 105, 52655273, 2000.

Crickmore, R. I.: A comparison between vertical winds and divergence in the high-latitude thermosphere, Ann. Geophys., 11, no. 8, 728-733, 1993.

Etemadi, A., Cowley, S. W. H., and Lockwood, M.: The effect of rapid changes in ionospheric flow on velocity vectors deduced from radar beam-swinging experiments, J. Atmos. Terr. Phys., 51, 125-138, 1989.

Foster, J. C.: An empirical electric field model derived from Chatanika radar data, J. Geophys. Res., 88, 981-987, 1983.

Greet, P. A., Conde, M. G., Dyson, P. L., Innis, J. L., Breed, A. M., and Murphy, D. J.: Thermospheric wind field over Mawson and Davis, Antarctica: simultaneous observations by two FabryPerot spectrometers of $630 \mathrm{~nm}$ emission, J. Atmos. Terr. Phys, 61, 1025-1045, 1999.

Griffin, E. M., Aruliah, A. L., Müller-Wodarg, I. C. F., and Aylward, A. D.: Comparison of high-latitude thermospheric meridional winds I: Optical and radar experimental comparisons, Ann. Geophys., 22, 849-862, 2004,

\section{SRef-ID: 1432-0576/ag/2004-22-849}

Innis, J. L. and Conde, M.: High-latitude thermospheric vertical wind activity from Dynamics Explorer 2 Wind and Temperature Spectrometer observations: Indications of a source region 
for polar cap gravity waves, J. Geophys. Res, 107, Issue A8, SIA 11-1, CiteID 1172, doi:10.1029/2001JA009130, 2002.

Ishii, M., Conde, M., Smith, R. W., Krynicki, M., Sagawa, E., and Watari, S.: Vertical wind observations with two FabryPerot interferometers at Poker Flat Alaska, J. Geophys. Res, 106, 10 537-10 551, 2001.

Killeen, T. L., Hays, P. B., Carignan, G. R., Heelis, R. A., Hanson, W. B., Spencer, N. W., and Brace, L. H.: Ion-Neutral Coupling in the High Latitude F-Region: Evaluation of Ion Heating Terms from Dynamics Explorer 2, J. Geophys. Res., 89, 7495-7508, 1984.

Killeen, T. L., Won, Y. -I., Niciejewski, R. J., and Burns, A. G.: Upper Thermosphere Winds and Temperatures in the Geomagnetic Polar Cap: Solar Cycle, Geomagnetic Activity and IMF Dependencies, J. Geophys. Res., 100, 21 327-21 342, 1995.

Lanchester, B. S., Kaila, K., and McCrea, I. W.: Relationship between large horizontal electric fields and auroral arc elements, J. Geophys. Res., 101, 5075-5084, 1996.

Lockwood, M., Cowley, S. W. H., Smith, M. F., Rijnbeek, R. P., and Elphic, R.C.: The contribution of flux transfer events to convection, Geophys. Res. Lett., 22, 1185-1188, 1995.

Makela, J. J., Kelley, M. C., Gonzalez, S. A., Aponte, N., and McCoy, R. P.: Ionospheric topography maps using multiple wavelength all-sky images, J. Geophys. Res., 106, 29 175-29184, 2001.

McCrea, I. W., Jones, G. O. L., and Lester, M.: The BEAN experiment - An EISCAT study of ion temperature anisotropies, Ann. Geophys., 13, 177-188, 1995,

SRef-ID: 1432-0576/ag/1995-13-177.

Millward, G. H., Moffett, R. J., Quegan, S., and Fuller-Rowell, T. J.: A coupled thermosphere-ionosphere-plasmasphere model (CTIP), STEP Handbook of ionospheric models, edited by Schunk, R. W., 1996.

Mozer, F. S.: Analysis of Techniques for Measuring DC and AC Electric Fields in the Magnetosphere, Space Sci. Rev, 14, 272313, 1973.

Oyama, S., Ishii, M., Murayama, Y., Shinagawa, H., Nozawa, S., Buchert, S. C., Fujii, R., and Kofman, W.: Generation of atmospheric gravity waves associated with auroral activity in the polar F-region, J. Geophys. Res., 106, 18 543-18 554, 2001.
Picone, J. M., Hedin, A. E., Drob, D. P., and Aikin, A. C.: NRLMSISE-00 empirical model of the atmosphere: Statistical comparisons and scientific issues, J. Geophys. Res, 107(A12), 1468, doi:10.1029/202JA009430, 2002.

Price, G. D., Smith, R. W., and Hernandez, G.: Simultaneous measurements of large vertical winds in the upper and lower thermosphere, J. Atmos. Terr. Phys. 57, 631-643, 1995.

Pryse, S. E.: Radio tomography: a new experimental technique, Surveys in Geophysics, 24, 1-38, 2003.

Rishbeth, H. and Williams, P. J. S.: The EISCAT Ionospheric Radar: the System and its Early Results, Q. J1. R. Astr. Soc., 26, 478$512,1985$.

Sakonoi, T., Fukunishi, H., Okano, S., Sato, N., Yamagishi, H., and Yukimatu, A.: Dynamical coupling of neutrals and ions in the high-latitude F-region: Simultaneous FPI and HF radar observations at Syowa Station, Antarctica, J. Geophys. Res., 107, A11, doi:10.1029/2001JA007530, 2002.

Schlegel, K., and St.-Maurice, J. P.: Anomalous heating of the polar E region by unstable plasma waves 1 . Observations, J. Geophys. Res., 86, 1447-1452, 1981.

Shematovich, V., Gerard, J.-C., Bisikalo, D. V., and Hubert, B.: Thermalization of $\mathrm{O}\left({ }^{1} \mathrm{D}\right)$ atoms in the thermosphere, J. Geophys. Res., 104, 4287-4295, 1999.

Shinagawa, H., Oyama, S., Nozawa, S., Buchert, S. C., Fujii, R., and Ishii, M.: Thermospheric and ionospheric dynamics in the auroral region, Adv. Space Res., 31, 951-956, 2003.

Sipler, D. P. and Biondi, M. A.: Simulation of hot oxygen effects on ground-based Fabry-Perot determinations of thermospheric temperatures, J. Geophys. Res., 108, A6, doi:10.1029/2003JA009911, 2003.

Solomon, S. C., Hays, P. B., and Abreu, V. J.: The auroral 6300A emission: Observations and modeling, J. Geophys.Res., 93, 9867-9882, 1988.

Thayer, J. P., Vickrey, J. F., Heelis, R. A., and Gary, J. B.: Interpretation and modelling of the high-latitude electromagnetic energy flux, J. Geophys. Res., 100, 19715-19728, 1995.

Weimer, D. R.: Models of High-Latitude Electric Potentials Derived with a Least Error Fit of Spherical Harmonic Coefficients, J. Geophys. Res., 100, 19 595-19607, 1995. 